\title{
AN ECONOMIC IMPACT OF INTEGRATED CONTROL PROGRAM OF COTTON CROPS IN GHARBIA GOVERNORATE
}

\author{
MUSTAFA, ALI RIZK ، OMAR AHMAD BADR \\ and NAGLAA ELSAID AHMED SHABAN
}

Agricultural Economics Research Institute, ARC, Doki, Giza.

(Manuscript received 17 January 2018)

\begin{abstract}
$\mathrm{T}$ he Agricultural production in Egypt is considered one of the most important productive sectors in national production, where most of its products of importance for food security in Egypt, the value of pesticides used in Egyptian agriculture is about $347.2,287.2,346.4$ million pounds at a rate estimated at $35.4 \%$, $29.3 \%, 35.3 \%$ for each of the pesticides and indigenous and grass on respectively of the total value of agricultural pesticides amounting to 980.8 million pounds in 201.6 The problem of the study focuses on the evaluation of economic and environmental impact on integrated pest management which afflict the cotton crops in Gharbia Governorate. The study aims to measure the economic and environmental impact of the use of integrated pest control of the production of cotton crops in Gharbia Governorate. The study showed that the most important factors affecting the production of the cotton crop in the first category, with the study sample in Gharbia governorate 2016 are: the amount of human labor, the quantity of seeds, the value of biological resistance the total productive elasticity amounted to about 0.867 that means the declining productive relationship, and the value of the marginal product of those elements of about 87.0, 249.3, 873.5 pound / kantar respectively, while the unit price of the element reached about 42.19, 5.39, 50.0 pound / unit respectively. In the second category and it was discovered that the most important factors affecting the cotton production are: the mechanical caber (irrigation), the quantity of seeds, chemical resistance Value and the productive elasticity total amounted to about 0.923 , while the value of marginal product of those elements toward 317.4, 423.2, 270.65 pound/ kantar respectively, while the unit price of the element toward 24.53, 5.43, 100.07 pounds / respectively, which refers to the efficiency of those elements in the equation of cotton production in the second category of study. The Study showed that: the nominal protection coefficient of production requirement, outputs, biological resistance, and effective protection coefficient of the cotton crop in the study sample year 2016 reached about 0.88 , $0.75,0.83,0.88$, whereas the domestic relative competitive coefficient (DRC) reached about 0.62 , this means there is relative competitive in cotton production in Egypt. The results of productive policy martin analysis for cotton crop year 2016, there is a negative impacts on the total feddan return, and added value. The study explained that the environmental impact of important pesticides
\end{abstract}


used by farmers of cotton and potato crop in sampling study of traditional insecticides in Gharbia governorate, came in the first rank sbedoo and mankozub pesticide with quantity of $0.29,0.58$ $\mathrm{kg} /$ feddan with safety period of 20,7 days respectively. As the pesticides developed comes in the first rank : marshal and polier .m.f with quantity of $0.84,0.5 \mathrm{~kg} /$ feddan with safety period 7,3 days respectively, the two pesticides non pollution to the environment, we conclude that the pesticides developed less harm to the environment than traditional insecticides.

\section{The recommendations}

1- It is necessary to educate the farmers with pesticide damage to human, animal and plant health and the environment.

2- The expansion in the use of the biological resistance in order to increase the quality of cotton, on one hand, and reducing the cost of chemical resistance on the other hand, for keeping the general health.

3- It should be setting a program for training cotton farmers on optimum using for pesticides in the allowable limits world wide for keeping the health of human, plant and the environment.

4- The imposition of a tax on users of highly toxic pesticides, which contributes to the transformation of the farmers to use clean agriculture, or setting a low to crime the using no useful.

5- It should stimulate cotton farmers that using pesticide at least scale and following the method of integrated control.

6- It is necessary to devise new cotton strains of high productivity and resistance to pests and supply the farmers with it and saved it for farmers to encourage them to increase the captivated area of cotton in Egypt. 


\title{
الأثر الإقتصادى لبرنامج المكافحة المتكاملة لمحصول القطن بمحافظة الغربية
}

\author{
علي رزق مصطفى ، عمر أحمد بدر و نجلاء السيد أحمد شعبان \\ معهز بحوث الإقتصاد الزراعي - مركز البحوث الزراعية - دقى - جيزه
}

\section{مقدمة}

يعتبر الإنتاج الزر اعى من أهم القطاعات الإنتاجية فى مصر ، حيث أن معظم منتجاته تمثل

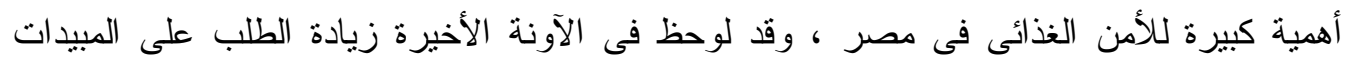

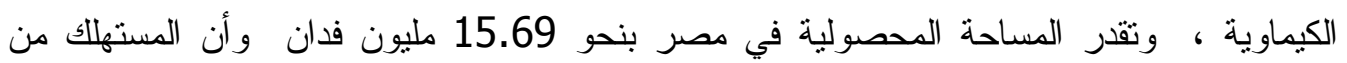
المبيدات علي هذه المساحة يقدر بنحو 8350 طن مبيدات ، تقدر قيمتها بنحو 980.8 مليون جنية عام 2016 موزعة كالتالي بين 3800 طن مبيدات حشرية ، 2750 طن مبيدات فطرية ، 1800 فئهن

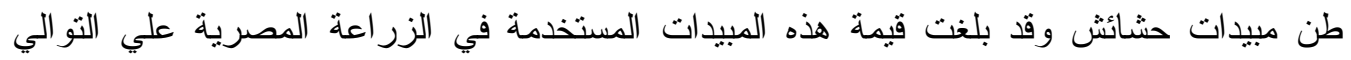
حو الي 347.2 ، 287.2 ، 346.4 مليون جنيها ، وبنسبة تقدر بنحو 35.4 \% ، 29.3 ، 35.4 ،

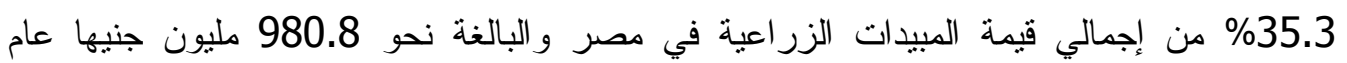

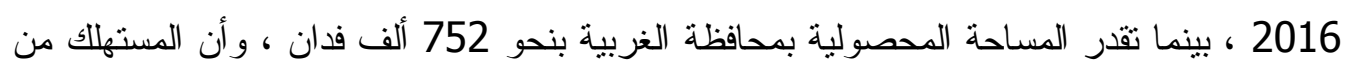
المبيدات علي هذه المساحة يقدر بنحو 3700 طن ، بمنل نحو 32\% من إجمالي كمية المبيدات

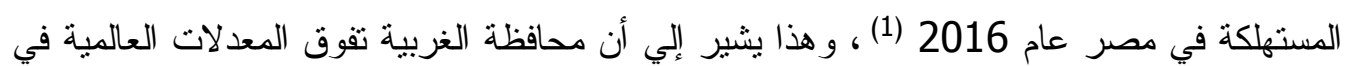
إستخدام المبيدات مما يؤثز علي مو اصفات المنتج.

\section{مشكلة الدراسة}

تعد المبيدات الكيماوية أحد مستلزمات الإنتاج الزراعي، إلا أنه تلاحظ في الآونة الأخيرة

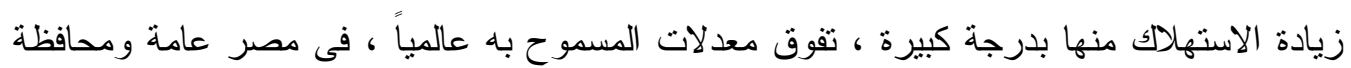
الغربية خاصة ، حيث تستهلك مصر كميات كبيرة من المبيدات تقدر بنحو 13 مرة ضعف بهاده

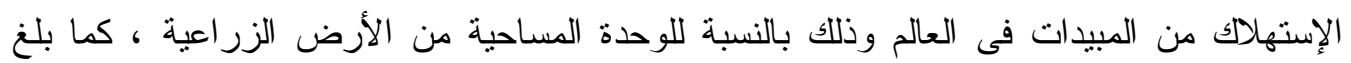
متوسط نصيب الفدان المزروع في مصر نحو 28.5 ، 10.7 ، 4.3 مرة ضعف الإستهلاك العالمي لكل من المبيدات الحشرية، الفطرية ، و الحشائش علي الترتيب ، فضلا عن ارتفاع أسعار المبيدات الزر اعية ، لذا فإن مشكلة الدراسة تركز علي تقييم الأثز الاقتصادي المترتب علي المكافحة المتكاملة

للآفات التي تصيب محصول القطن بمحافظة الغربية وأثز ذلك علي الصحة العامة و البيئة .

$$
\text { أهداف الدر اسة }
$$

تهدف الدراسة إلي قياس الأثر الاقتصادي لاستخدام المكافحة المنكاملة علي إنتاج محصول القطن بمحافظة الغربية من خلال الأهداف الفرعية الثالية : 
- - تطور المساحة والإنتاجية والإنتاج الكلي وتكلفة المكافحة الكيماوية و البيولوجية و المتكاملة

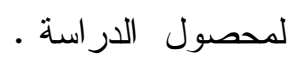

- - دراسة دو ال إنتاج القطن بفئات العينة ، و أثز المكافحة المتكاملة على الإنتاج •

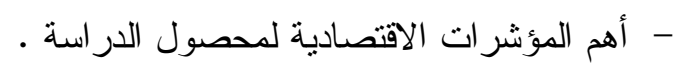

- قياس الآثار المترنبة علي برنامج المكافحة المتكاملة من خلال تطبيق مصفوفة تحليل

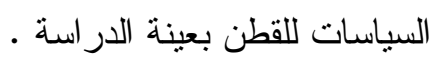

\section{الأسلوب البحثي ومصادر البيانات}

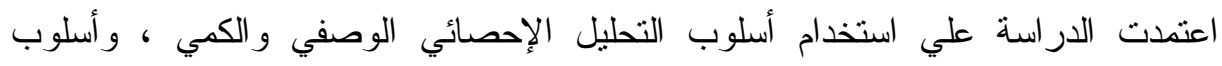

الانحدار البسيط و المتعدد ، كما اعتمدت الدراسة علي إجراء التقييم المالي و الاقتصادي للسياسة الإسية الإنتاجية لمحصول القطن بمحافظة الغربية وذلك من خلال تطبيق مصفوفة تحليل السياسات قبل وبعد تطبيق المكافحة المتكاملة لمحصول القطن ـ وقد اعتمدت الدراسة علي مصدرين أساسيين للبيانات ، أولها بيانات أولية لعينة ميدانية مختارة لأهم مركزين بالمحافظة وفقا للأهمية النسبية للمساحات المزروعة من القطن. وثانيها البيانات الثانوية المنشورة وغير المنشورة بسجلات إدارة الإحصاء ، وقسم المكافحة الحقلية و البستانية بمديرية الزر اعة بمحافظة الغربية.

\section{اختيار عينة الار اسة}

تم اختبار مركزى المحلة الكبرى وقطور وفقاً لأهميتها النسبية حيث بمثلان نحو 72.5 \% ، 13 \% 13.7 \% من إجمالي مساحة القطن بالمحافظة البالغة نحو 5188 فدان قطن عام 2016 - جدول

كما تم اختيار أكبر قريتين فى كل مركز وفقاً للمساحة المزروعة بالقطن فكانت قريتى :

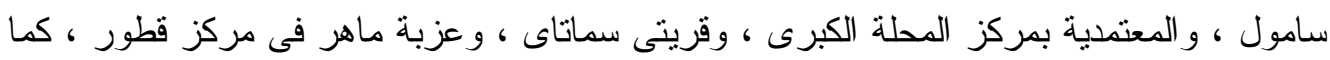

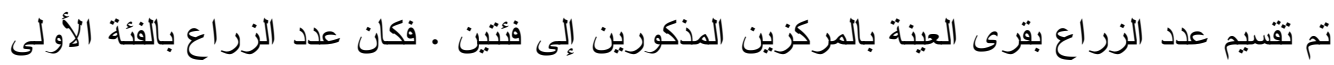

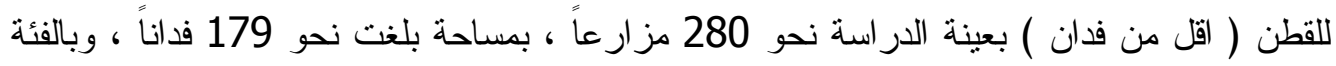

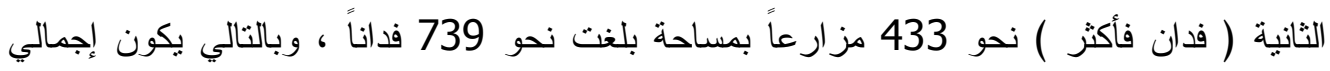

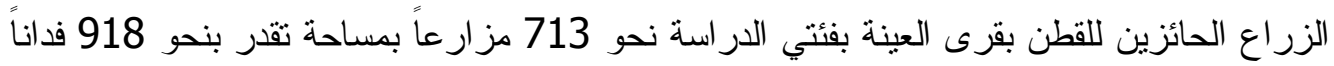

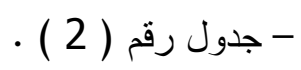

ونم تحديد حجم العينة وفقاً للقانون بنحو 120 مشاهدة(1) ، فكان عدد المشاهدات المختارة

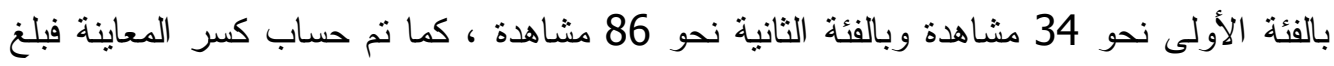

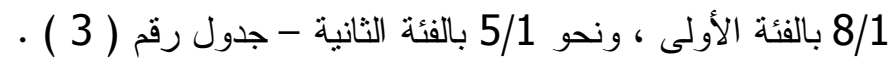


جدول رقم (1) : الأهمية النسبية لمر اكز إنتاج القطن في محافظة الغربية عام 2016

\begin{tabular}{|c|c|c|c|c|c|}
\hline$\%$ & عدد الزراع & $\%$ & (المساحة & المركز & ? \\
\hline 6.7 & 364 & 6.3 & 327 & طنطا & 1 \\
\hline 71.5 & 3881 & 72.5 & 3762 & المحلة الكبري & 2 \\
\hline 13.7 & 744 & 13.7 & 712 & قطور & 3 \\
\hline 1.4 & 76 & 1.3 & 67 & زفتي & 4 \\
\hline 0.3 & 16 & 0.3 & 14 & السنطة & 5 \\
\hline 0.1 & 6 & 0.1 & 5 & كفر الزيات & 6 \\
\hline 6.2 & 339 & 5.8 & 301 & بسيون & 7 \\
\hline---- & ---- & ---- & --- & سمنود & 8 \\
\hline 100 & 5426 & 100 & 5188 & الإجمالي & \\
\hline
\end{tabular}

المصدر : جمعت وحسبت من مديرية الزر اعة بالغربية ، سجلات إدارة المكافحة الحقلية ، بيانات غير منشورة .

جدول رقم (2) : إجمالي المساحة المزروعة قطن بالقرى المختارة بمركزي العينة بمحافظة الغربية موسم 2016

\begin{tabular}{|c|c|c|c|c|c|c|c|c|}
\hline \multicolumn{2}{|c|}{ الفئة الثانية } & \multicolumn{2}{|c|}{ الفئة الأولي } & \multirow{2}{*}{ المزالقطن } & \multirow[b]{2}{*}{ علد المزارعين } & \multirow[b]{2}{*}{ القري المختارة } & \multirow[b]{2}{*}{ المركز } & \multirow[b]{2}{*}{ p } \\
\hline المسلحة & الحائزين & العساحة & الحائزين & & & & & \\
\hline 309 & 156 & 28 & 37 & 337 & 193 & سامول & \multirow{2}{*}{ الكبري } & 1 \\
\hline 278 & 185 & 50 & 58 & 328 & 243 & المتصدية & & 2 \\
\hline 587 & 341 & 78 & 95 & 665 & 436 & \multicolumn{3}{|c|}{ الجملــــــــة } \\
\hline 92 & 50 & 50 & 100 & 142 & 150 & سماتاي & \multirow{2}{*}{ قطور } & 3 \\
\hline 60 & 42 & 51 & 85 & 111 & 127 & عزبة ماهر & & 4 \\
\hline 152 & 92 & 101 & 185 & 253 & 277 & \multicolumn{3}{|c|}{ الجملــــــــة } \\
\hline 739 & 433 & 179 & 280 & 918 & 713 & \multicolumn{3}{|c|}{ إجمالى } \\
\hline
\end{tabular}

المصدر : جمعت وحسبت من مديرية الزر اعة بالغربية ، سجلات إدارة الإحصاء ، بيانات غير منشورة .

جدول رقم (3) : نوزيع عينة الدراسة المختارة من الحائزين لمساحات القطن علي فئات العينة بمحافظة الغربية موسم 2016 .

\begin{tabular}{|c|c|c|c|c|c|c|c|c|c|c|}
\hline كسل (") & علدا الحائزين & الهلنس & الهلسي & نسبة العنزين فيد & $\begin{array}{c}\text { المسادة } \\
\text { \% } \\
\text { \% }\end{array}$ & 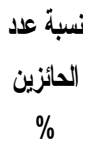 & بالفان & الحانزين & الفئت & $p$ \\
\hline$\frac{1}{8}$ & 34 & 28.35 & 27.67 & 765.77 & 19.50 & 39.27 & 179 & 280 & الأولي : أقلّل من فـان & 1 \\
\hline$\frac{1}{5}$ & 86 & 71.65 & 69.92 & 4888.77 & 80.50 & 60.73 & 739 & 433 & الثانية : فان فأكثر & 2 \\
\hline & 120 & 100 & 97.59 & ----- & 100 & 100 & 918 & 713 & \multicolumn{2}{|l|}{ الإجمالي } \\
\hline
\end{tabular}

(") يستخدم كسر المعاينة لتوزيع العينة علي القري المختارة بجدول رقم (4) .

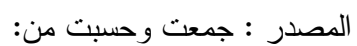

1- مديرية الزر اعة بالغربية ، سجلات إدارة الإحصاء ، بيانات غير منشورة .

2- الإدارة الزر اعية بمركزى المحلة الكبري وقطور ، سجلات إدارة الإحصاء ، بيانات الإنات غير منشورة . 
وتم توزيع عينة الدر اسة على قرى العينة المختارة وفقاً لكسر المعاينة فكان نصيب قريتى

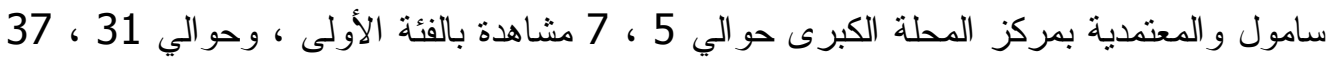
مشاهدة بالفئة الثانية على التزتيب وكان نصيب قريتى سماتاى ، وعزبة ماهر بمركز قطور حو الي

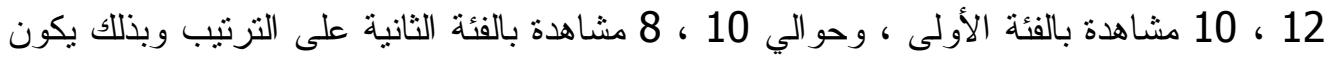
إجمالي المشاهدات بالفئة الأولى بقرى العينة حو الي 34 مشاهدة ، وبالفئة الثانية حو الي 86 مشاهدة ، وبذلك يكون إجمالى العينة لمزارعى القطن بالقرى المذكورة فى مركزى الدراسة حوالي 120

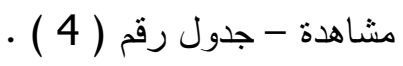

جدول رقم (4) : نوزيع عينة الدر اسة علي قري العينة المختارة وفقا لحجم الفئة بمز ارع القطن بمحافظة الغربية موسم 2016

\begin{tabular}{|c|c|c|c|c|c|c|c|c|c|c|c|c|}
\hline \multicolumn{5}{|c|}{ فذان فأكثر } & \multicolumn{5}{|c|}{ أقل من فـان } & \multirow[b]{2}{*}{ القرية } & \multirow[b]{2}{*}{ المركز } & \multirow[b]{2}{*}{ p } \\
\hline الحتائزين & $\%$ & بالفان & $\%$ & الحائزين & الحنتارين & $\%$ & بالفان & $\%$ & الحائزين & & & \\
\hline 31 & 41.8 & 309 & 36.0 & 156 & 5 & 15.6 & 28 & 13.2 & 37 & سامول & \multirow{2}{*}{ الكبري } & \multirow{2}{*}{1} \\
\hline 37 & 37.6 & 278 & 42.7 & 185 & 7 & 27.9 & 50 & 20.7 & 58 & المتثدية & & \\
\hline 10 & 12.5 & 92 & 11.5 & 50 & 12 & 27.9 & 50 & 35.7 & 100 & سماتاي & \multirow[b]{2}{*}{ قطور } & \multirow[b]{2}{*}{2} \\
\hline 8 & 8.1 & 60 & 9.7 & 42 & 10 & 2.75 & 51 & 30.4 & 85 & عزهر & & \\
\hline 86 & 100 & 739 & 100 & 433 & 34 & 100 & 179 & 100 & 280 & & الإجم & \\
\hline
\end{tabular}

المصدر : جمعت وحسبت من :

1- مديرية الزر اعة ، سجلات إدارة الإحصاء ، بيانات غير منشورة .

2-الإدارة الزراعية بمركزى المحلة الكبري وقطور ، سجلات إدارة الإحصاء ، بيانات غير منشورة .

\section{النتائج البحثية}

- الوضع الراهن لتطور الإتتاج وتكلفة المكافحة المتكاملة لمحصول القطن بمحافظة الغزبية

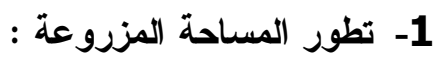

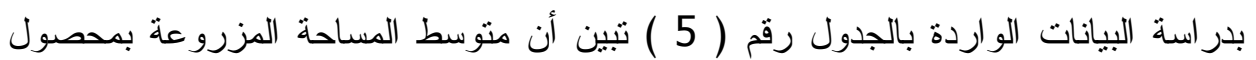

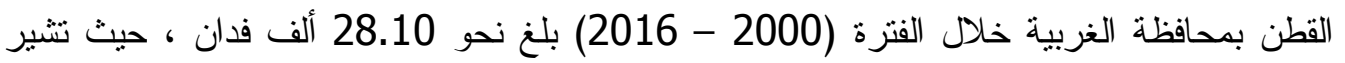
المعادلة رقم (1) بالجدول (6) إلى وجود اتجاهاً عاماً تتاقصياً معنوي إحصائياً في المساحة المزروعة عند مستوى معنوية ( المان ) ) ، بمقدار تناقص سنوي بلغ نحو 2.805 ألف فدان وبمعدل

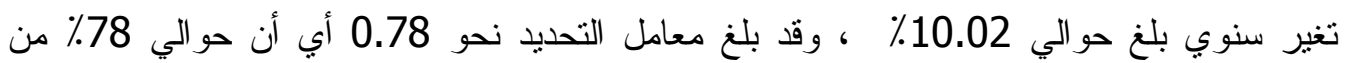


التغير ات الحادثة في المساحة المزروعة بمحصول القطن بمحافظة الغربية نعزى إلى التغيرات التي يعكس أثز ها عامل الزمن و الباقي يرجع إلي عو امل غير مدروسة. 2- 2 تطور الإنتاجية الفداتية:

ويتضح من بيانات الجدول رقم (5) أن منوسط الإنتاجية الفدانية لمحصول القطن في محافظة

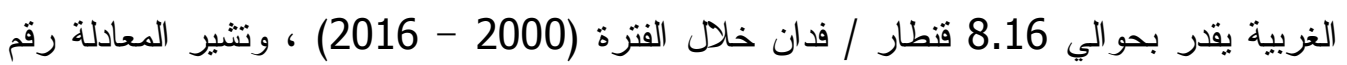
(2) بالجدول (6) إلى أنها غير معنوية إحصائياً في الإنتاجية الفدانية لمحصول القطن بمحافظة

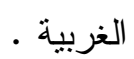

\section{3- تطور الطاقة الإتاجية:}

يبين الجدول رقم (5) أيضاً أن منوسط الطاقة الإنتاجية لمحصول القطن بمحافظة الغربية بلغ نحو 224.05 ألف قنطار خلال الفترة (2000 - 2016) ، حيث تشير المعادلة رقم (3) بالجدول (6) إلى وجود اتجاها عاماً تتاقصياً معنوي إحصائياً في الطاقة الإنتاجية لمحصول القطن بمحافظة الغربية عند مسنوى معنوية ( 0.01 ) ، بمقدار تتاقص سنوي بلغ نحو 20.17 ألف قنطار وبمعدل

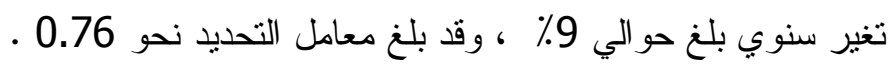
4- تطور تكلفة المقاومة الكيماوية لمحصول القطن:

بدراسة البيانات الواردة بالجدول رقم (5) تبين أن متوسط تكلفة المقاومة الكيماوية لمحصول القطن بمحافظة الغربية خلال الفترة (2000 - 2016) بلغ نحو حيث تثير المعادلة رقم (4) بالجدول (6) إلى وجود اتجاهاً عاماً متز ايداً معنوي إحصائياً في تكلفة المقاومة الكيماوية عند مستوى معنوية (0.01) ، بمقدار تز ايد سنوي بلغ نحو 22.88 جنيه/فدان

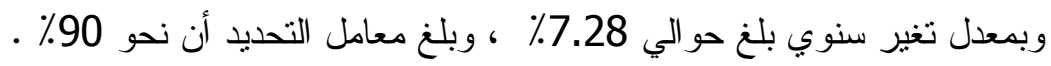
5- تطور تكلفة المقاومة البيولوجية لمحصول القطن:

توضح بيانات الجدول رقم ( 5 ) أن متوسط تكلفة المقاومة البيولوجية لمحصول القطن

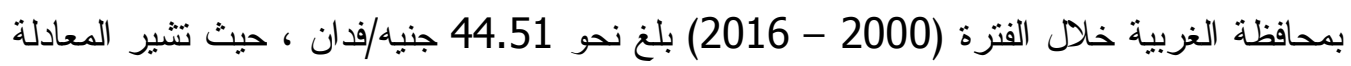
رقم (5) بالجدول (6) إلى وجود اتجاهاً عاماً متز ايداً معنوي إحصائياً في تكلفة المقاومة البيولوجية

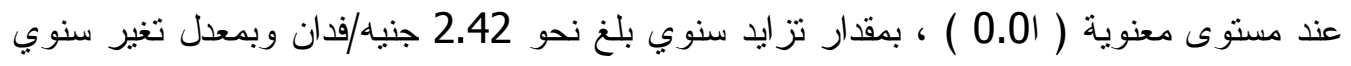

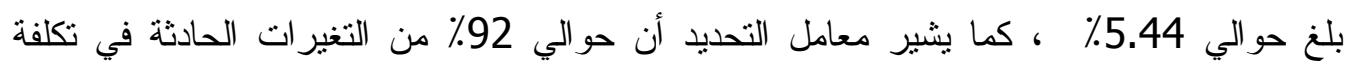
المقاومة البيولوجية بمحصول القطن بمحافظة الغربية تعزى إلى التغيرات التي يعكس أثزها عامل مئل ك- الزمن و الباقي يرجع إلي عوامل غير مدروسة. 6 - تطور إجمالي تكلفة المكافحة المتكاملة لمحصول القطن: بدر اسة البيانات الو اردة بالجدول رقم ( 5) تبين أن منوسط إجمالي تكلفة المكافحة المتكاملة

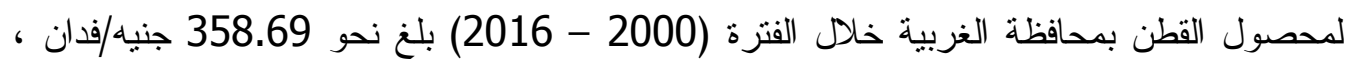
حيث تشير المعادلة رقم (6) بالجدول (6) إلى وجود اتجاهاً عاماً متز ايداً معنوي إحصائياً في إجمالي

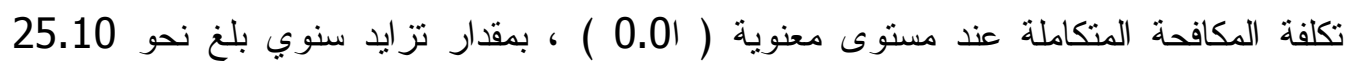

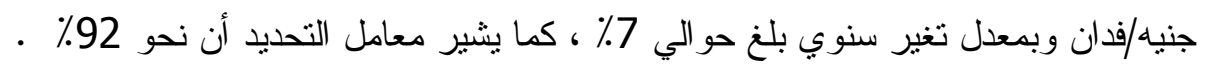


جدول رقم (5) : نطور المساحة والإنتاجية والإنتاج وتكلفة المكافحة المتكاملة

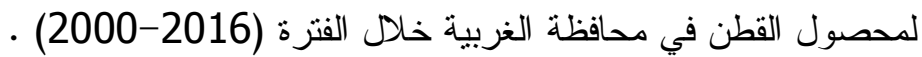

\begin{tabular}{|c|c|c|c|c|c|c|}
\hline إجمالي تكلفة المكافحة & تكلفة المقاومة & تكلفة المقاومة & (أنتاج قتطار) & 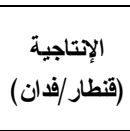 & مساحة القطن فدان) & السنوات \\
\hline 235.4 & 25.4 & 210 & 276.4 & 7.86 & 35.17 & 2000 \\
\hline 215.5 & 30.5 & 185 & 341.8 & 5.95 & 57.50 & 2001 \\
\hline 190.5 & 25.5 & 165 & 448.2 & 7.82 & 57.34 & 2002 \\
\hline 180.8 & 30.8 & 150 & 310.6 & 8.34 & 37.24 & 2003 \\
\hline 263.7 & 35.7 & 228 & 358.5 & 7.53 & 47.59 & 2004 \\
\hline 248.5 & 40.5 & 208 & 317.6 & 8.33 & 38.14 & 2005 \\
\hline 324.6 & 44.6 & 280 & 274.3 & 9.28 & 29.55 & 2006 \\
\hline 320.5 & 45.5 & 275 & 319.6 & 8.79 & 36.35 & 2007 \\
\hline 325.8 & 40.8 & 285 & 142.3 & 8.25 & 17.24 & 2008 \\
\hline 344.5 & 44.5 & 300 & 142.2 & 8.42 & 16.89 & 2009 \\
\hline 365.6 & 45.6 & 320 & 155.5 & 8.50 & 18.26 & 2010 \\
\hline 390.5 & 50.5 & 340 & 229.5 & 8.90 & 25.79 & 2011 \\
\hline 515.4 & 55.4 & 460 & 134.7 & 8.00 & 16.84 & 2012 \\
\hline 520.5 & 50.5 & 470 & 106.7 & 9.22 & 11.57 & 2013 \\
\hline 538.3 & 58.3 & 480 & 143.8 & 8.43 & 17.06 & 2014 \\
\hline 550.7 & 60.7 & 490 & 61.37 & 6.07 & 10.11 & 2015 \\
\hline 566.9 & 71.9 & 495 & 45.70 & 8.96 & 5.10 & 2016 \\
\hline 358.69 & 44.51 & 314.18 & 224.05 & 8.16 & 28.10 & المتوسط \\
\hline
\end{tabular}

المصدر : جمعت وحسبث من :

1- مديرية الزر اعة بالغربية ، سجلات إدارة الإحصاء ، بيانات غير منشورة .

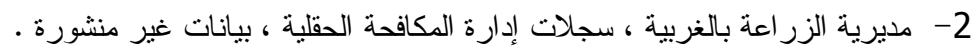

جدول رقم (6) : معادلات الإتجاه الزمني العام للمساحة المزروعة و الإنتاجية الفدانية و الطاقة الإنتاجية وبنود تكاليف المكافحة المتكاملة لمحصول القطن في محافظة الغربية خلال الفترة (2000 - 2016)

\begin{tabular}{|c|c|c|c|c|c|c|c|}
\hline $\mathbf{F}$ & $R^{2}$ & معلل التغير السنوي." & المتوسط & المعادلة & & البيان & i \\
\hline $52.679 * *$ & 0.778 & 10.02 & 28.10 & $\hat{y}_{1}=53.347-2.805 x_{i}$ & $(-7.258)^{* *}$ & المساحة المزروعة & 1 \\
\hline 1.040 & 0.065 & 5.76 & 8.16 & $\hat{y}_{2}=7.729+0.47 x_{i}$ & $(1.020)$ & الإتتاجية الفانية & 2 \\
\hline $48.407 * *$ & 0.763 & 9.00 & 224.05 & $\hat{y}_{3}=405.568-20.169 x_{i}$ & $(-6.958)^{* *}$ & الطاقة الإتابية & 3 \\
\hline $139.153^{* *}$ & 0.903 & 7.28 & 314.18 & $\hat{y}_{4}=108.28+22.88 x_{i}$ & $(11.796)^{* *}$ & تكلةة العقاوهة الكيلموية & 4 \\
\hline $164.513^{* *}$ & 0.916 & 5.44 & 44.51 & $\hat{y}_{5}=22.71+2.42 x_{i}$ & $(12.826)^{* *}$ & تكلفة المقاومة البيولوجية & 5 \\
\hline $162.160 * *$ & 0.915 & 7.00 & 358.69 & $\hat{y}_{6}=132.16+25.10 x_{i}$ & $(12.734)^{* *}$ & إجملي تكلفة المكاففة التكايلة & 6 \\
\hline
\end{tabular}

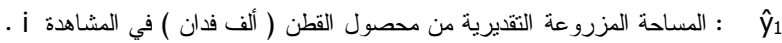

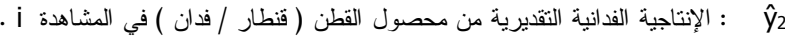

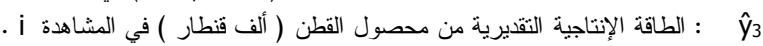

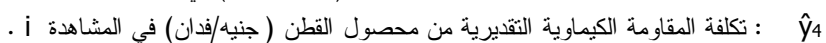

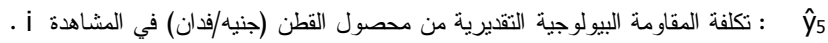

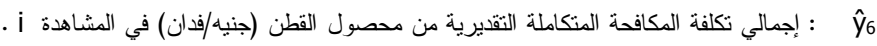

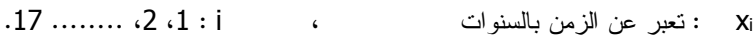

المصدر : حسبت من بيانات جدول رقم (5) بالدر اسة. 
تم إدخال عوامل الإنتاج كمتغير ات مستقلة علي الحاسب الآلي وهي : مقدار العمل البشري

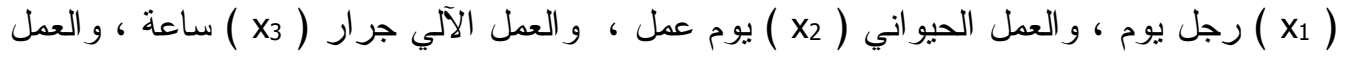

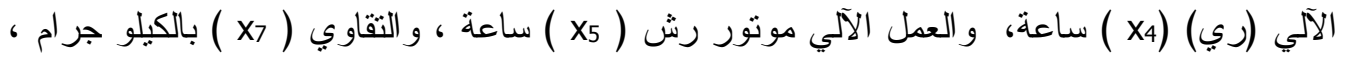

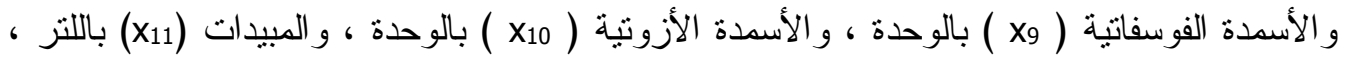
وقيمة المقاومة البيولوجية (x12i) بالجنيه ، وكمية الانتاج (y) بالقنطار كمتغير تابع ، ونم إختيار

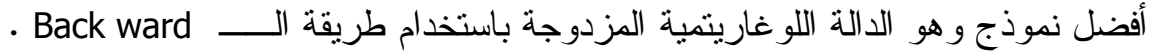

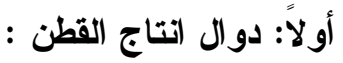
1- دالة إنتاج القطن في الفئة الأولي :

بدراسة المعادلة رقم (1) بالجدول (7) بالفئة الأولي فقد تبين أن هناك علاقة دالية لو غاريتمية مزدوجة بين الناتج من القطن (ل⿳亠丷厂

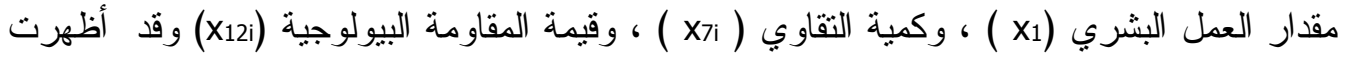

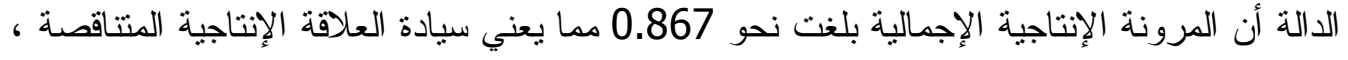
أي أن زيادة الموارد الإجمالية بالدالة المقدرة بنسبة 10\% تؤدي إلي زيادة الإدة كمية الناتج من القطن

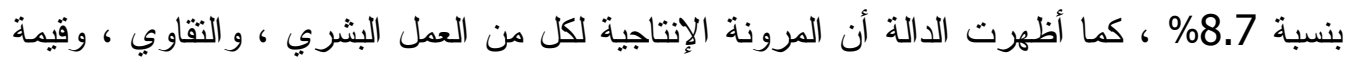

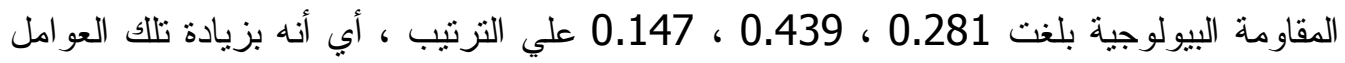

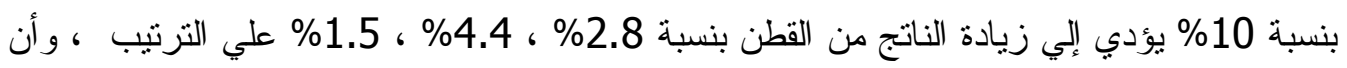

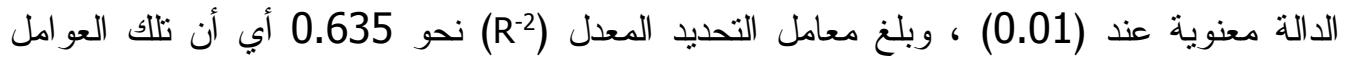
بالدالة تفسر نحو 64\% من العوامل المحددة لإنتاج القطن في هذه الفئة و الباقي يرجع إلي عو امل غير مدروسة.

هذا وقد بلغ الناتج الحدي للعناصر بالدالة : العمل البشري ، و التقاوي ، و والمقاومة

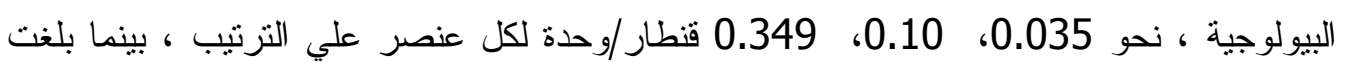
قيمة الناتج الحدي لتلك العناصر نحو 87.0، 249.3 ، 873.5 جنيه / قنطار للعناصر المذكورة

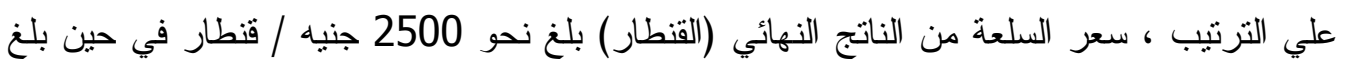

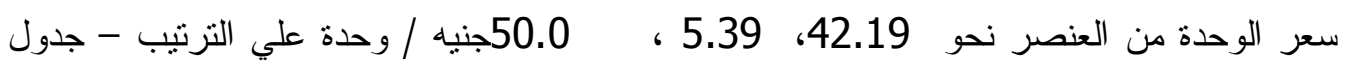

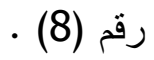

وحيث أن قيمة الناتج الحدي لتلك العو امل أكبر من سعر الوحدة منها ، مما يشير إلي كفاءة

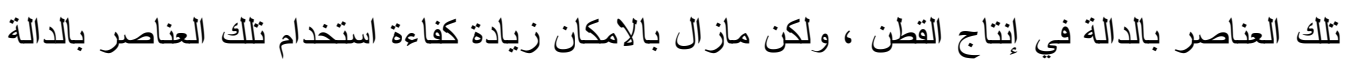
حتى تتساوى قيمة الناتج الحدى مع سعر العنصر فى السوق. 2- دالة إنتاج القطن في الفئة الثانية : بدر اسة المعادلة رقم (2) بالجدول (7) فقد تبين أن هناك علاقة دالية لوغاريتمية مزدوجة بين

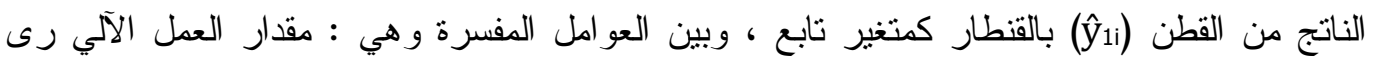

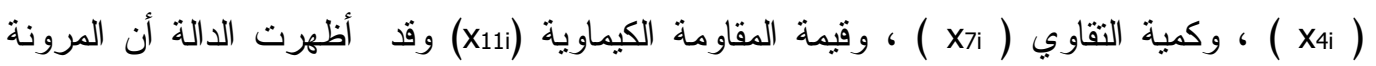

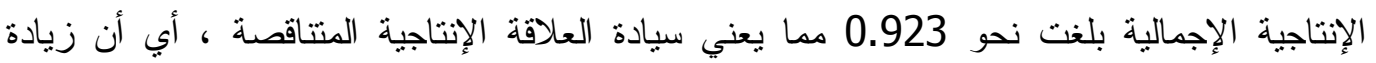


المو ارد الإجمالية بالدالة المقدرة بنسبة 10\% تؤدي إلي زيادة كمية الناتج من القطن بنسبة 9.23\% ،

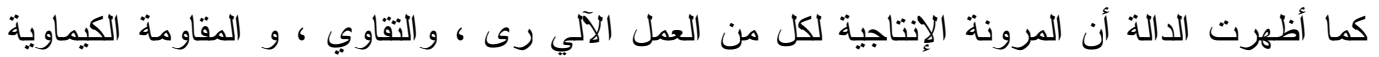

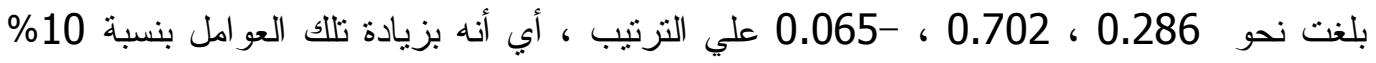
يؤدي إلي زيادة الناتج من القطن بنسبة 2.9\% ، 7.02\% ، -0.65\% علي الترتيب ـ وكانت الدالة معنوية عند (0.01) ، وبلغ معامل التحديد المعدل (R-2) نحو 0.81 أي أن تلك العو امل بالدالة تفسر

نحو 81\% من العوامل المحددة لإنتاج القطن في هذه الفئة و الباقي برجع إلي عوامل غير مقيسة .

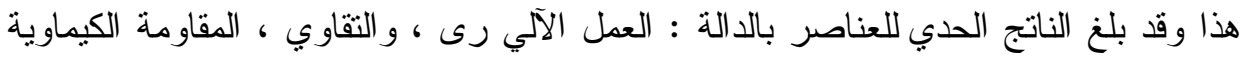
نحو 0.129 0.172 ، 0.110 لكل عنصر علي التزتيب ، بينما بلغت قيمة الناتج الحدي لتلك العناصر نحو 317.4، 423.2 ، 270.65 جنيه / قنطار من العناصر المذكورة علي الترتيب ، و سعر السلعة من الناتج النهائي (القنطار) بلغ 2500 جنيه / قنطار ، في حين بلغ سعر الوحدة من العنصر نحو 24.53 ، 5.43، 100.07 جنيه/وحدة علي الترتيب - جدول رقم (8) ـ وحيث أن قيمة الناتج الحدي لتلك العو امل أكبر من سعر الوحدة منها ، مما يشبر إلي كفاءة تلك العناصر بالدالة في إنتاج القطن ، ولكن ماز ال بالامكان زيادة كفاءة استخدام تلك العناصر بالدالة حتى نتساوى قيمة

$$
\text { الناتج الحدى مع سعر العنصر فى السوق. }
$$

جدول رقم (7) : دالة إنتاج القطن قي فئتي عينة الدراسة بمحافظة الغربية عام 2016

\begin{tabular}{|c|c|c|c|c|c|c|}
\hline المعنوية & F المحسوية & $\mathbf{R}^{2}$ & المرونة - الإجمالية & المعادلة المقلرة & الفئة & p \\
\hline ** & 20.140 & 0.635 & 0.867 & $\begin{aligned} L \hat{Y}_{1 i}= & -0.615+0.281 L X_{1 i}+0.439 L X_{7 i}+0.147 L X_{12 i} \\
& (-3.641)^{* *}(2.864)^{* *}(3.945)^{* *}(1.743)\end{aligned}$ & 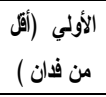 & 1 \\
\hline *** & 122.500 & 0.811 & 0.923 & $\begin{aligned} L \hat{Y}_{1 i}=- & 0.563+0.286 L X_{4 i}+0.702 L X_{7 i}-0.065 L X_{11 i} \\
& (-7.446)(4.930)^{* *}(11.245)(-1.297)\end{aligned}$ & 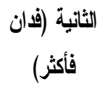 & 2 \\
\hline
\end{tabular}

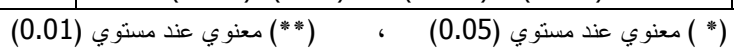

i كمية القطن التقديرية المنتجة في فئتي عينة الدراسة بالقنطار في المشاهدة :

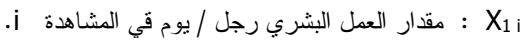

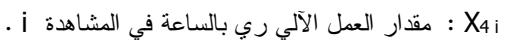

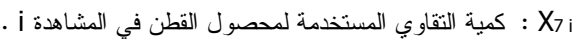

كمية المبيدات المستخدمة بالتر في المشاهدة أ X

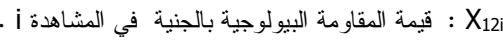

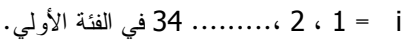

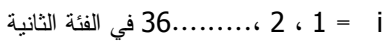

= Log 
جدول رقم (8) : الكفاءة الإقتصادية لعناصر إنتاج القطن بعينة الدر اسة

بمحافظة الغربية عام 2016

\begin{tabular}{|c|c|c|c|c|c|c|c|c|c|c|}
\hline الإقتصادية & بالجنئ & لقاتليمة & 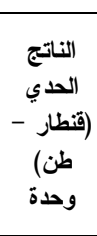 & $\begin{array}{c}\text { المتوسط } \\
\text { (قنطار } \\
\text { الناتن) }\end{array}$ & المرونة & اللهنصر & اللوغناريتمي & العنصر & $\begin{array}{c}\text { متوسط الإتتاج } \\
\text { (ف) }\end{array}$ & |الفئة | \\
\hline ** & 42.19 & 87.00 & 0.0348 & 0.124 & 0.281 & 28.184 & 1.4500 & $X_{1}$ & \multirow{3}{*}{$\begin{array}{c}0.5431868 \\
\text { (3.493) } \\
\text { قنطار }\end{array}$} & \multirow{3}{*}{ 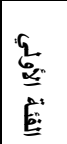 } \\
\hline ** & 5.39 & 249.25 & 0.0997 & 0.227 & 0.439 & 15.374 & 1.1868 & $x_{7}$ & & \\
\hline ** & 50.00 & 873.50 & 0.3494 & 2.377 & 0.147 & 36.543 & 1.5628 & $X_{12}$ & & \\
\hline ** & 24.53 & 317.40 & 0.129 & 0.450 & 0.286 & 19.711 & 1.2947 & $X_{4}$ & \multirow{3}{*}{$\begin{array}{c}0.9481564 \\
(8.875) \\
\text { قنطار }\end{array}$} & \multirow{3}{*}{ E } \\
\hline ** & 5.43 & 423.20 & 0.172 & 0.245 & 0.702 & 36.191 & 1.5586 & $X_{7}$ & & \\
\hline *"* & 100.07 & 270.65 & 0.110 & 1.695 & 0.065 & 5.236 & 0.7190 & $X_{11}$ & & \\
\hline
\end{tabular}

متوسط سعر السلعة من الناتج النهائي (قنطار القطن) في الفئة الأولي = 2500 جنيه / قنطار ، في الفئة الثانية = 2460.47 جنيه / 24.710 / قنطار . المصدر : حسبت من الجدول رقم (7) بالدر اسة.

ثانياً: أثر المكافحة المتكاملة - الكيماوية و البيولوجية - علي إنتاج القطن : 1 الفئة الأولي : 1

بدر اسة المعادلات الواردة بالجدول رقم (9) تبين وجود علاقة طردية لوغاريتمية مزدوجة

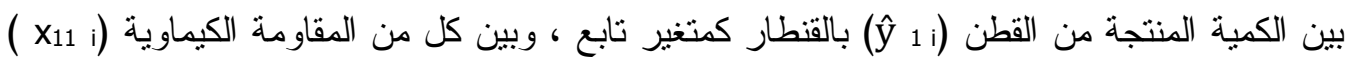

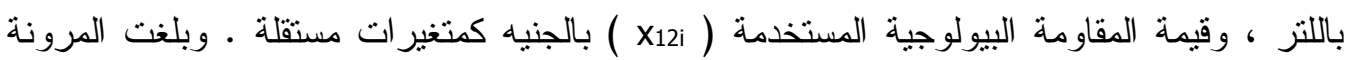

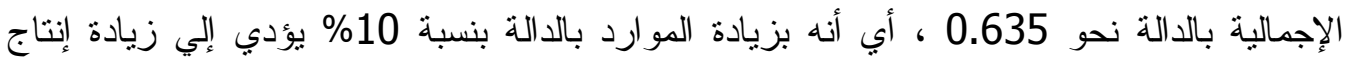

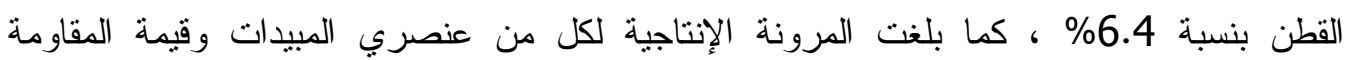

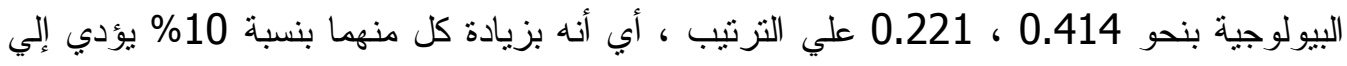
زيادة إنتاج القطن بنسبة 4.14\% ، 2.21\% علي التزتيب ، وقد ثبت معنوية الدالة عند مستوي

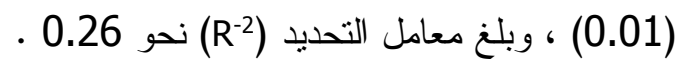

كما بلغ الناتج الحدي لعنصري المبيدات ، و المقاومة البيولوجية نحو 0.067 ، 0.021

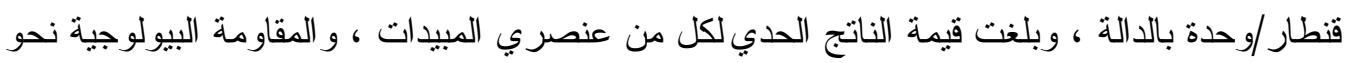
167.5 ، 52.5 جنيه /وحدة ، كما بلغ منوسط سعر الوحدة من عنصري المبيدات ، وقيمة

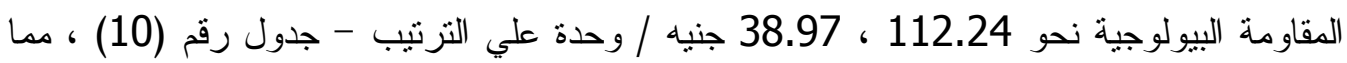

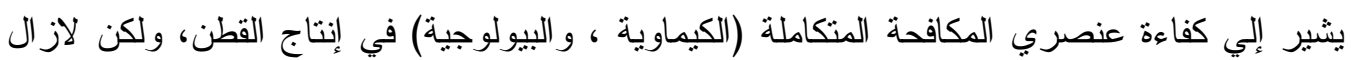

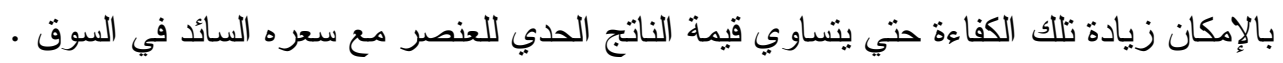
2- الفئة الثانية:

بدر اسة المعادلات الواردة بالجدول رقم (9) تبين وجود علاقة طردية لوغاريتمية مزدوجة

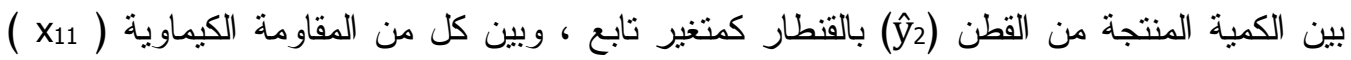

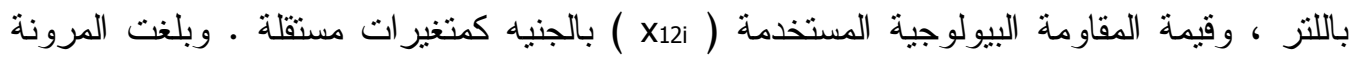

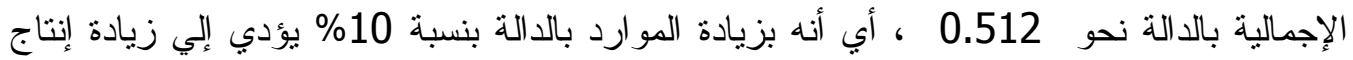
القطن بنسبة 5.12\% ، كما بلغت المرونة الإنتاجية لكل من عنصري المبيدات وقيمة المقاومة 
البيولوجية بنحو 0.128 ، 0.384 علي التزتيب ، أي أنه بزيادة كل منهما بنسبة 10\% يؤدي إلي زيادة إنتاج القطن بنسبة 1.28\% ، 3.84\% علي الترتيب، وقد ثبت معنوية الدالة عند مستوي

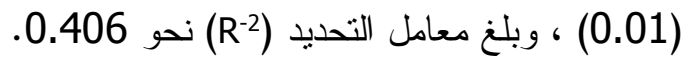

كما بلغ كمية الناتج الحدي لعنصري المبيدات، و المقاومة البيولوجية نحو 0.204 ، 0.057 ، 0. قنطار /وحدة بالدالة ، وبلغت قيمة الناتج الحدي لكل من عنصري المبيدات ، و المقاومة البيولوجية نحو 510 ، 142.5 جنيه /وحدة ، كما بلغ منوسط سعر الوحدة من عنصري المبيدات ، و المقاومة البيولوجية نحو 100.1 ، 58.95 جنيه / وحدة علي التزنيب - جدول رقم (10) ـ مما يشير إلي كفاءة عنصري المكافحة المتكاملة (الكيماوية ، و البيولوجية) في إنتاج القطن، ولكن لاز ال بالإنكان زيادة تلك الكفاءة حتي ينساوي قيمة الناتج الحدي للعنصر مع سعره السائد في السوق .

جدول رقم (9) : أثر المقاومة الكيماوية والبيولوجية علي إنتاج القطن بعينة الدراسة بمحافظة الغربية عام 2016

\begin{tabular}{|c|c|c|c|c|c|}
\hline المنوية & F المحسوية & $\overline{\mathbf{R}^{2}}$ & الإجمالية & المعادلة & الفئة \\
\hline$* *$ & 5.526 & 0.263 & 0.635 & $\begin{array}{rl}L \hat{Y}_{1 i} & =0.060+0.414 L X_{11}+ \\
(2.707)^{* *} & 0.221 L^{*}(1.878)\end{array}$ & الأولي (ألّل من فدان ) \\
\hline$* *$ & 18.356 & 0.406 & 0.512 & $\begin{array}{r}L \hat{Y}_{2 i}=-0.158+0.128 L X_{11 i}+ \\
(2.443)^{*}\end{array}$ & الثاثية (فان فأكثر ) \\
\hline
\end{tabular}

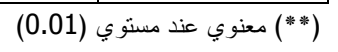

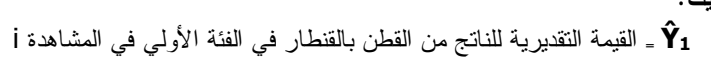

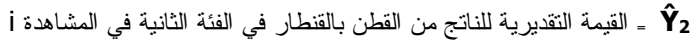

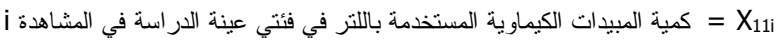

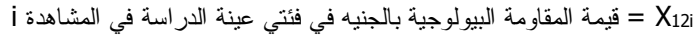

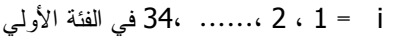

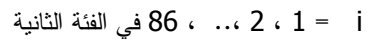

$$
\begin{aligned}
& \text { log = L }
\end{aligned}
$$

المصدر : جمعت وحسبت من استمار ات استيان العينة.

جدول رقم (10) : الكفاءة الإقتصادية لعنصري المقاومة الكيماوية (المبيدات) و البيولوجية

\begin{tabular}{|c|c|c|c|c|c|c|c|c|c|c|}
\hline الإقتصادية & بالجنيه & الناتجة & الداتج & المتوسط & المرونة & اللهندسي الوسط & اللوغاريتمي اللوسط & العنصر & $\begin{array}{l}\text { متوسط الإتاج } \\
\text { (|⿳亠丷厂巾1) }\end{array}$ & الفئة \\
\hline ** & 112.24 & 167.50 & 0.067 & 0.1614 & 0.414 & 2.17 & 0.3365 & $X_{11}$ & \multirow{2}{*}{$\begin{array}{c}0.54469 \\
(3.505)\end{array}$} & \multirow{2}{*}{ الأولي } \\
\hline$* *$ & 38.97 & 52.50 & 0.021 & 0.096 & 0.221 & 36.54 & 1.5628 & $X_{12}$ & & \\
\hline$* *$ & 100.10 & 510.0 & 0.204 & 1.591 & 0.128 & 5.24 & 0.7190 & $X_{11}$ & \multirow{2}{*}{$\begin{array}{c}0.9211 \\
(8.339)\end{array}$} & \multirow{2}{*}{ الثانية } \\
\hline$* *$ & 58.95 & 142.5 & 0.057 & 0.149 & 0.384 & 55.92 & 1.7476 & $X_{12}$ & & \\
\hline
\end{tabular}
المستخدمة في إنتاج القطن بعينة الدراسة بمحافظة الغربية عام 2016

متوسط سعر السلعة من الناتج النهائي (قنطار القطن) في الفئة الأولي = 2500 جنيه / قنطار ، في الفئة الثانية = 2500 جنيه / قنطار المصدر : حسبت من الجدول رقم (9) بالدراسة. 
ثالثاً: بعض المقاييس الإقتصادية لفدان محصول القطن بفئتي عينة الدراسة بمحافظة الغربية: بدراسة الجدول رقم (11) تبين أن الكمية المنتجة من محصول القطن في الفئتين الأولي

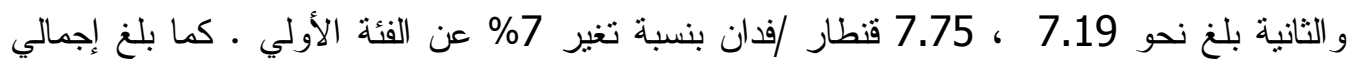

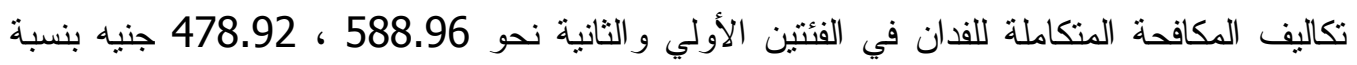
تغير بلغت نحو -33\% عن الفئة الأولي، كما بلغ إجمالي التكاليف الكلية للفدان في الفئتين الأولي

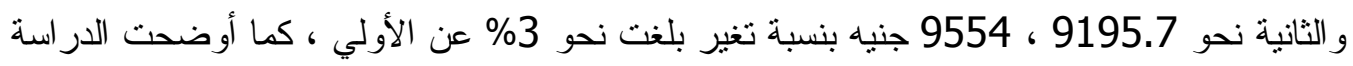
أن تكلفة كل من المقاومة الكيماوية (المبيدات) و المقاومة البيولوجية وإجمالي تكلفة المكافحة المتكاملة تمتل نحو 5.54\% ، 0.86\% ، 6.40\% من إجمالي التكاليف الكلية لفدان القطن في الفئتين الأولي

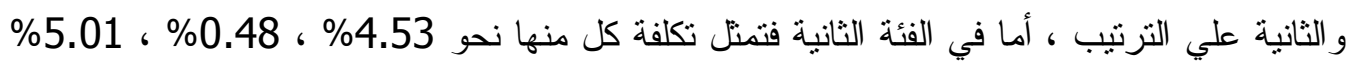
من إجمالي التكاليف الكلية لفدان القطن علي الترنيب، وبلغ صافي العائد للفدان في الفئتين المذكورتين

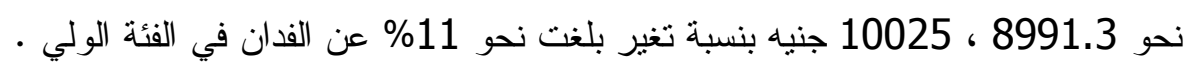

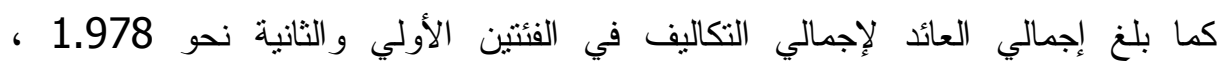
2.049علي الترتيب، كما بلغ عائد الجنيه المستثر نحو 0.978 ، 1.049 في الفئنين الألئ الأولي و الثانية علي الترتيب، وبلغ مقدار الربح فوق التكاليف المتغيرة في الفئنين الأولي والثانية نحو

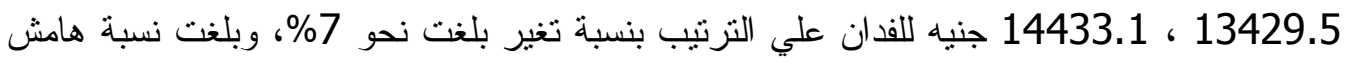

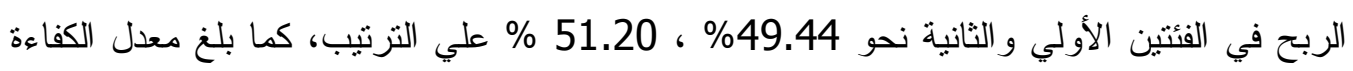

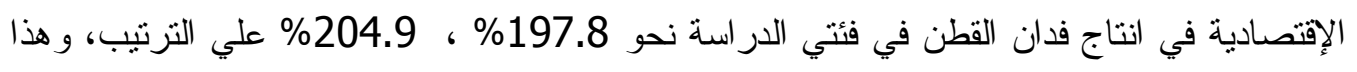
يعكس وفورات السعة في الفئة الثانية (فدان فأكثر) عن الفئة الأولي (الأقل من فدان) . - مصفوفة تحليل السياسة الإنتاجية القطنية بعينة الاراسة :

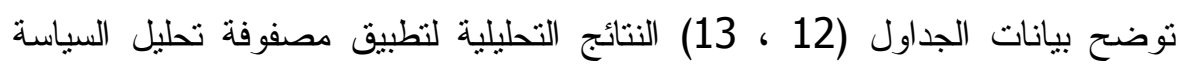
الإنتاجية القطنية بعينة الدراسة بالغربية في ظل تطبيق برنامج المكافحة المتكاملة لمحصول

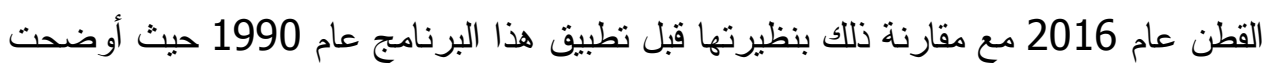

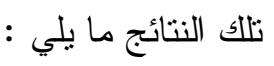
- أن معامل الحماية الإسمي لمستلزمات إنتاج فدان القطن يقدر بنحو 0.88 وهذا يعني وجود دعم لتلك المستلزمات يقدر بنحو 12\% من السعر العالمي لقيمة هذه المستلزمات و البالغ حو الي لئي

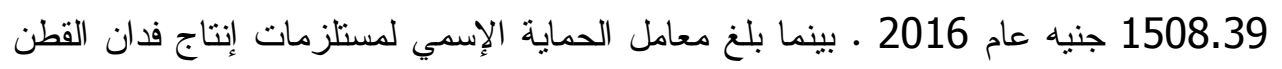

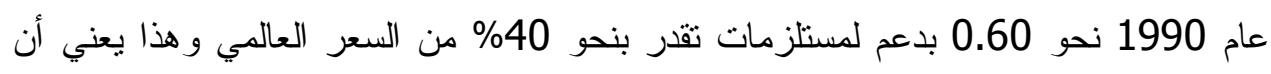

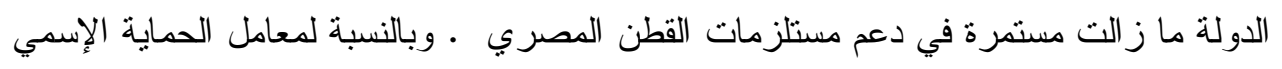

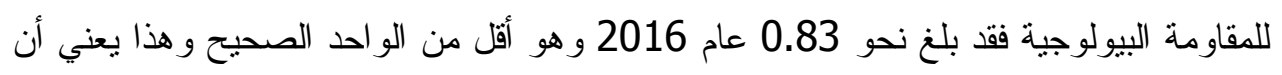

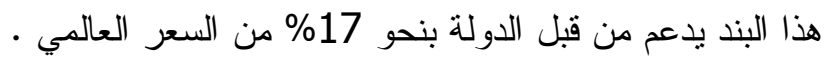

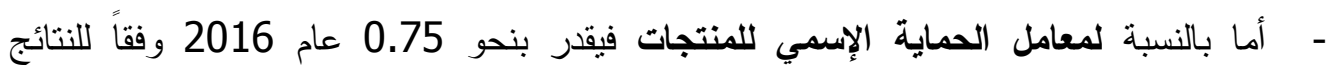
التحليلية بالمصفوفة بالعينة وهو أكبر من نظيره المقدر بنحو 0.43 عام 1990 مما بعنى التئي

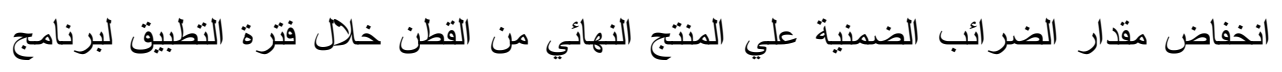


وفيما ينطق بمعامل الحماية الفعال فقد قدر بنحو 0.88 عام 2016 في ظل تطبيق برنامج المكافحة المتكاملة بالمقارنة بنظيره المقدر بنحو 0.85 عام 1990 قبل الفيل التطبيق و هذا يؤكد

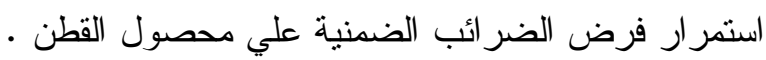

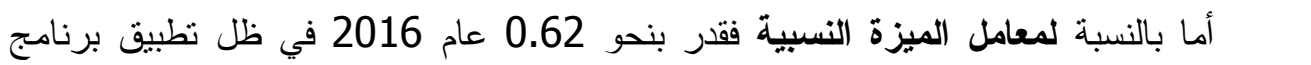

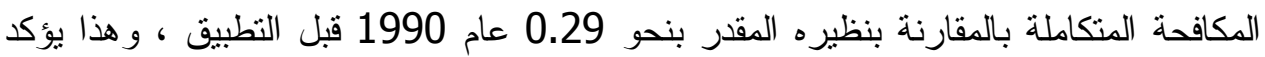
أيضا أنه لاز الت لمصر ميزة نسبية في إنتاج وتصدير القطن المصري لمان لما له من مميز ات في في

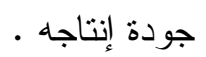
ومما يجب الإثشارة إليه أن أهم النتائج التحليلية لكصفوفة السياسات الإنتاجية قد أظهرت وجود

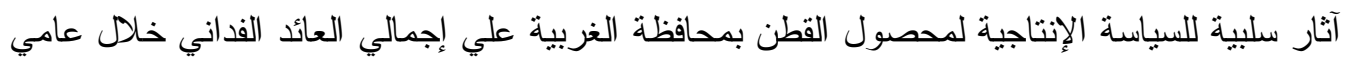

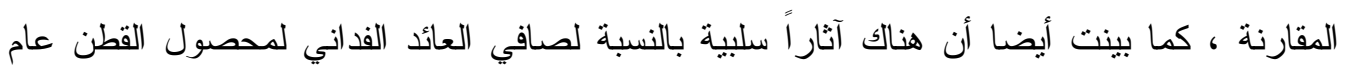

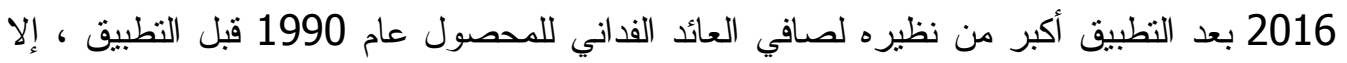

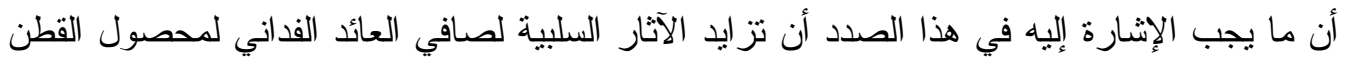

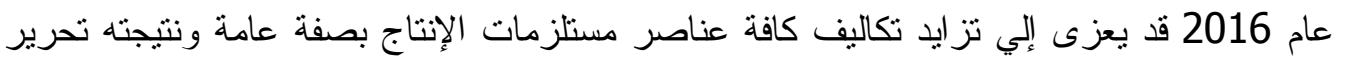

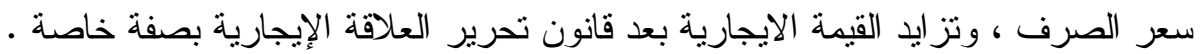

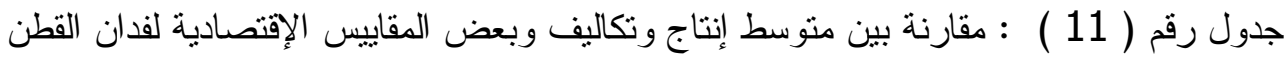
بفئتي عينة الدراسة بمحافظة الغربية عام 2016

( النكاليف : بالجنية )

\begin{tabular}{|c|c|c|c|}
\hline 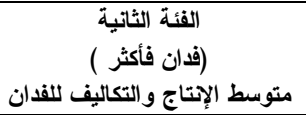 & 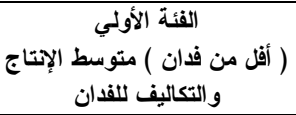 & 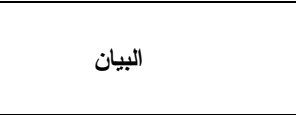 & s \\
\hline $\mathbf{1}$ & $\mathbf{1}$ & المسناحة & 1 \\
\hline 7.75 & 7.19 & كمية الإتتاج بالقتطار & 2 \\
\hline 2934.30 & 2537.00 & تكلفة العمل البشرى & 3 \\
\hline 20.94 & 3.53 & تكلفة العمل الحيواني & 4 \\
\hline 830.70 & 813.0 & إجمالي تكلفة العمل الآلي & 5 \\
\hline 3785.69 & 3353.70 & إجمالي تكلفة العمل المزرعى & 6 \\
\hline 432.64 & 509.90 & تكلفة المبيدات & 7 \\
\hline 46.28 & 79.06 & تكلفة المقاومة البيولوجية & 8 \\
\hline 478.92 & 588.96 & إجمالي تكلفة المكافحة المتكاملة & 9 \\
\hline 1360.20 & 1403.80 & إجمالي تكلفة مستلزمات الإتتاج & 10 \\
\hline 5145.90 & 4757.50 & التكاليف المتغيرة & 11 \\
\hline 4408.10 & 4438.20 & التكاليف الثابتة & 12 \\
\hline 9554.00 & 9195.70 & التكاليف الكلية & 13 \\
\hline 19579.00 & 18187.00 & إجمالي العائد & 14 \\
\hline 10025.00 & 8991.30 & صافي العائد & 15 \\
\hline 2.049 & 1.978 & إجمالي العائد لإجمالي التكاليف & 16 \\
\hline 1.049 & 0.978 & عائد الجنية المستثمر & 17 \\
\hline 14433.10 & 13429.50 & الربح فوق التكاليف المتغيرة & 18 \\
\hline 10025.00 & 8991.30 & هامش الربح & 19 \\
\hline$\% 51.20$ & $\% 49.44$ & نسبة هامش الربح للمنتج \% & 20 \\
\hline$\% 204.90$ & $\% 197.80$ & معدل الكفاعة الإقتصادية \% & 21 \\
\hline
\end{tabular}

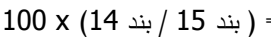

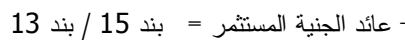

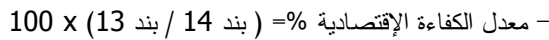


جدول رقم (12) مقارنة مصفوفة تحليل السياسات الإنتاجية لمحصول القطن بعينة الدراسة

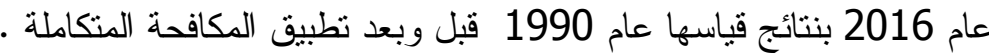

\begin{tabular}{|c|c|c|c|c|c|c|c|c|c|c|c|c|c|c|}
\hline \multicolumn{7}{|c|}{ عام 1990 (قبل التطبيق) } & \multicolumn{7}{|c|}{ عام 2016 (في ظل تطبيق البرنامج) } & \\
\hline \multirow{2}{*}{ 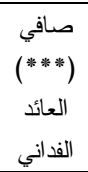 } & \multirow[b]{2}{*}{ إجمالي العائد } & \multicolumn{3}{|c|}{ المو ارد المحلية } & \multicolumn{2}{|c|}{ مستلزمات الإنتاج } & \multirow[b]{2}{*}{ صافي (العائد الفداني } & \multirow[b]{2}{*}{ إلجمالي العائد } & \multicolumn{3}{|c|}{ المو ارد المحلية } & \multicolumn{2}{|c|}{ مستازمات الإنتاج } & \\
\hline & & الجملة & الأرض & عنصر & جملة (***") & 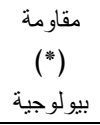 & & & الجملة & الأرض & عنصر & 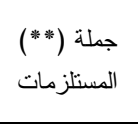 & 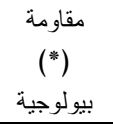 & الهيليم \\
\hline 410 & 1305 & 646 & 129 & 517 & 79 & - & 9508.15 & 18883 & 7992.97 & 4423.15 & 3569.82 & 1330.33 & 62.67 & 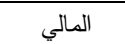 \\
\hline 480.1 & 3007.16 & 2224.7 & 1901 & 323.7 & 132.36 & - & 10843.89 & 25303.22 & 12899.25 & 10150 & 2749.25 & 15088.39 & 75.20 & الإقتصادي \\
\hline$(70.1)$ & $(1702.16)$ & $(1578.7)$ & (1772) & 193.3 & $(53.36)$ & - & $(1335.74)$ & $(6420.22)$ & $(4906.28)$ & $(5726.85)$ & 820.57 & $(178.06)$ & $(12.53)$ & أثر السياسة \\
\hline
\end{tabular}

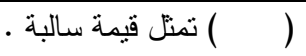

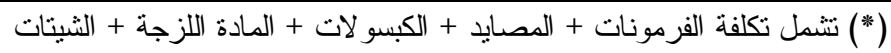

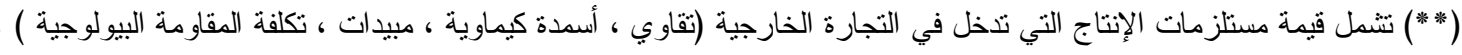

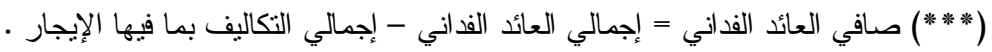
المصدر : جمعت وحسبت من الجدول رقم (1) بالملدق.

جدول رقم (13) : مقارنة نتائج قياس مصفوفة تحليل السياسات لمحصول القطن بعينة الدر اسة

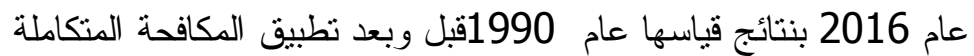

\begin{tabular}{|c|c|c|c|c|c|c|c|c|c|}
\hline \multicolumn{5}{|c|}{ العينة (في ظل تطبيق البرنامج ) عام 1990} & \multicolumn{5}{|c|}{ العينة (في ظل تطبيق البرنامج ) عام 2016} \\
\hline \multirow{3}{*}{ معامل الميزة } & \multirow{3}{*}{ معامل الحماية } & \multicolumn{3}{|c|}{ معامل الحماية الإسمي } & \multirow{3}{*}{ معامل المبزة } & \multirow{3}{*}{ معامل الحماية } & \multicolumn{3}{|c|}{ معامل الحماية الإسمي } \\
\hline & & \multirow{2}{*}{ ل للمنتجات } & \multicolumn{2}{|c|}{ للمستلزمات } & & & \multirow{2}{*}{ 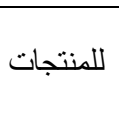 } & \multicolumn{2}{|c|}{ للمستلزمات } \\
\hline & & & جملة المستلزمات & مقاومة بيولوجية & & & & جملة المستلزمات & مقاومة بيولوجية \\
\hline 0.29 & 0.85 & 0.43 & 0.60 & - & 0.62 & 0.88 & 0.75 & 0.88 & 0.83 \\
\hline
\end{tabular}

المصدر : جمعت وحسبت من الجدول رقم (1) بالملحق . 
أهم المبيدات المستخدمة من قبل الزارع بكثافة لمحصول القطن بعينة الاراسة بمحافظة الغربية أولاً : المبيدات التقليدية :

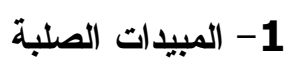

توضح بيانات جدول (14) أهم المبيدات التقليدية الصلبة المستخدمة من قبل الز ارع بأسلوب

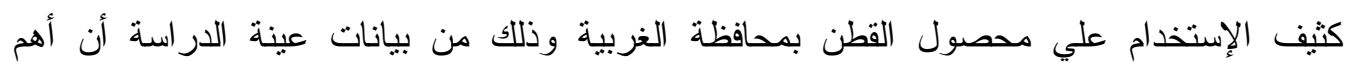

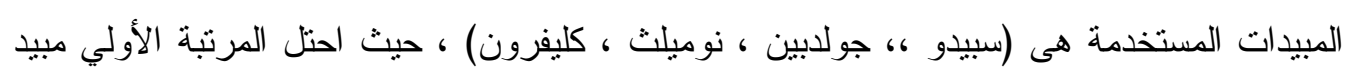

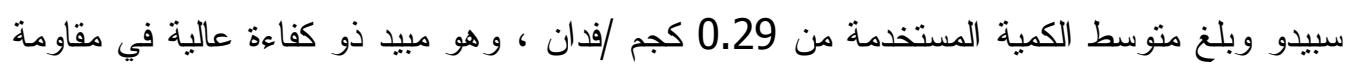

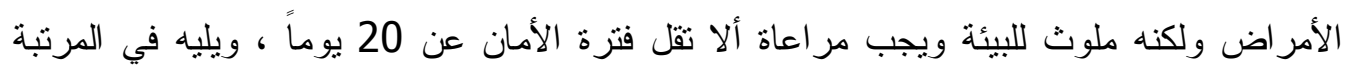

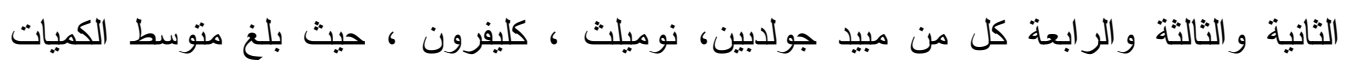

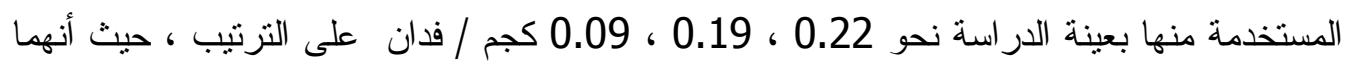

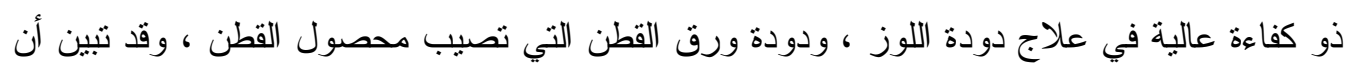

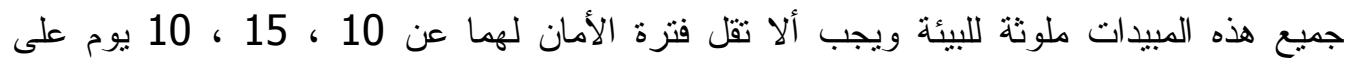

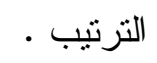

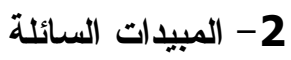

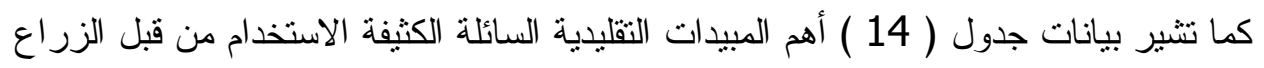

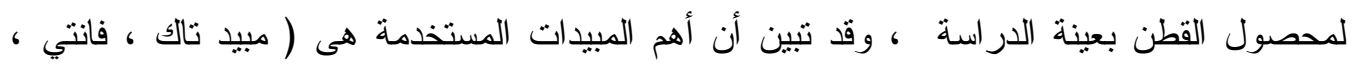

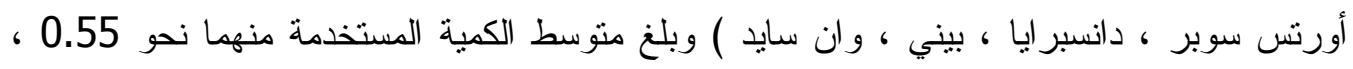

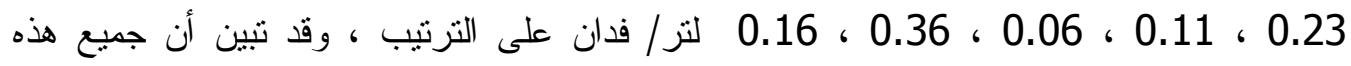
المبيدات ملوثة للبيئة ، مع مر اعاة ألا تقل فترة الأمان لها عن 20.23 ، 20.06 ، 20 ، 20 ، 15 ، 15 ، 7 ، 25 أيام على التزتيب. 
جدول رقم ( 14): يوضح المبيدات التقليدية الكثيفة الإستخدام من قبل الزراع لمحصول القطن بعينة الدراسة موسم 2016

\begin{tabular}{|c|c|c|c|c|c|c|c|c|}
\hline البيئة & تصنيف السمية"(") & البيئة البموعة & فترة الأمان & الترتيب في & متوسط الكمية (بالكجم) & معدل الاستخدام & الأمراض & المبيا \\
\hline ملوث & 11 & أصفر & 20 & الأول & 0.29 & 250 جم / 100لتر ماء & دودة اللوز وورق القطن & سبيلاو سيل \\
\hline ملوث & 11 & أصفر & 15 & 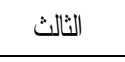 & 0.19 & 300 جم /600نتر ماء & دودة ورق القطن & جولالبين \\
\hline ملوث & 11 & أصفر & 10 & الر ابع & 0.09 & 250 جم /100 لنز ماء & دودة ورق القطن & نوميلث \\
\hline ملوث & 11 & أصفر & 10 & الثناني الثي & 0.22 & 350جم / 400 لتر ماء & دودة ورق القطن & كليفرون \\
\hline \multicolumn{9}{|c|}{ إجملي كبة المبيدات الصلبة المستخدة للفان 0.79 كجم 89 جنبة متوسط سعر الكيلو 112.5 جنية } \\
\hline ملوث & 11 & أصفر & 20 & الأول & 0.55 & 1 & 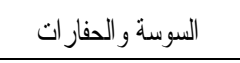 & تأك \\
\hline 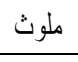 & 11 & أصفر & 20 & الثالث & 0.23 & 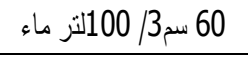 & 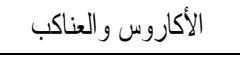 & فانتي \\
\hline 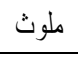 & 11 & أصفر & 20 & 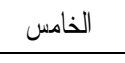 & 0.11 & 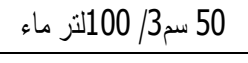 & 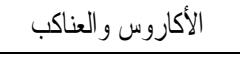 & 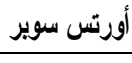 \\
\hline 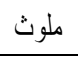 & 11 & أصفر & 15 & 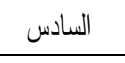 & 0.06 & 40 سم3/100لتر ماء & الأكاروس & دانسبرايا \\
\hline ملوث & 11 & أصفر & 7 & الثاني & 0.36 & 150 سم/ 600نثر ماء & دودة ورق القطن & بيني \\
\hline ملوث & 11 & أصفر & 25 & الر ابع & 0.16 & 1 لتزر / 200 لتز ماء & الحشائش & وان سلي \\
\hline
\end{tabular}

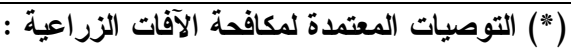

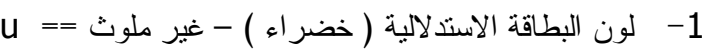

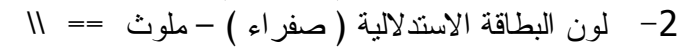

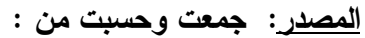

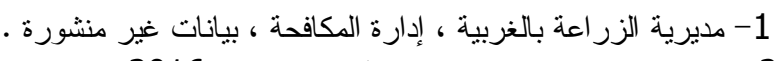

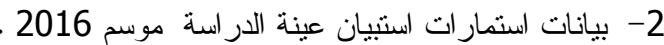




\section{ثانياً: : المبيدات المستحدثة : \\ 1}

توضح بيانات جدول (15) أهم المبيدات التقليدية الصلبة المستخدمة من قبل الزارع بأسلوب

كثيف الإستخدام علي محصول القطن بمحافظة الغربية وذلك من بيانات عينة الدراسة أن أهم المبيدات المستخدمة هى (موسييلان ، أوشين ، مارشال) ، حيث احتل المرتبة الأولي مبيد مارشال

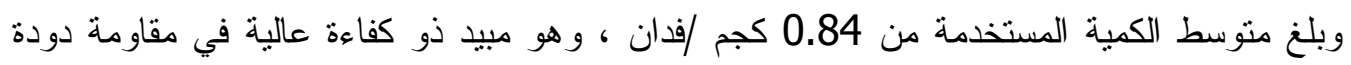

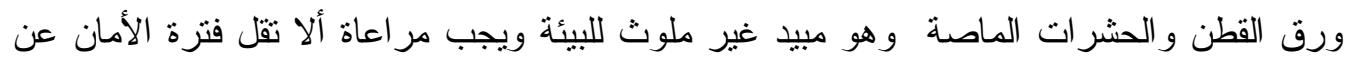

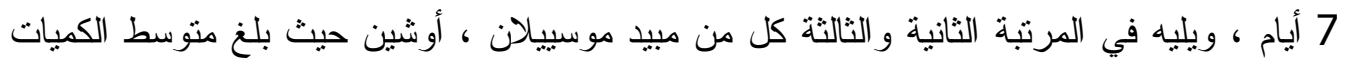

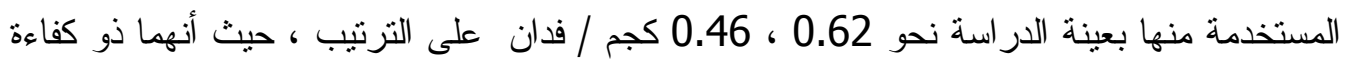
عالية في مقاومة الحشرات الماصة ، و المن ، و التربس التي تصيب محصول القطن، و هما مبيدان

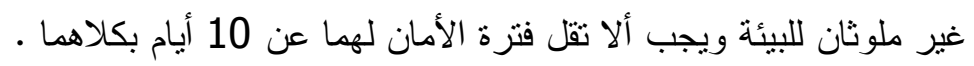

\section{2- المبيدات السائلة}

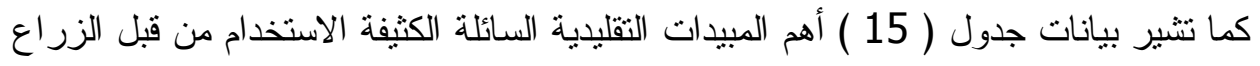

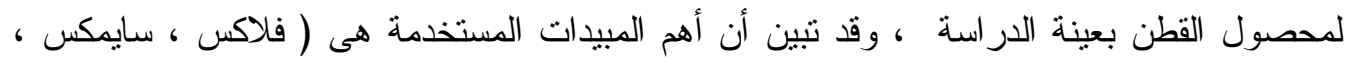

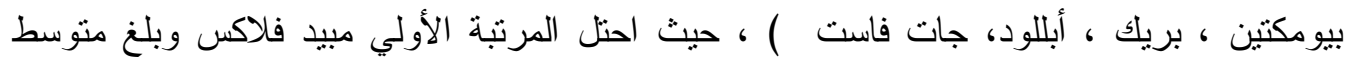

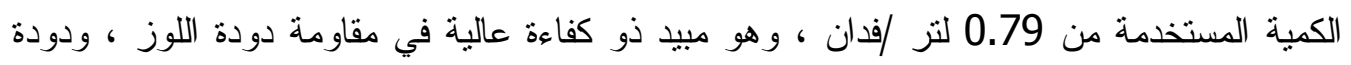

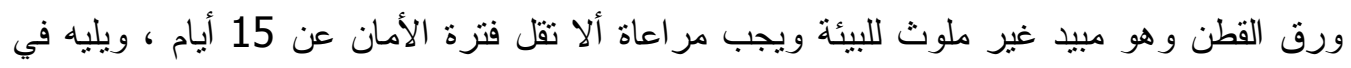

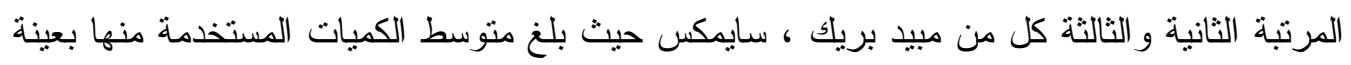

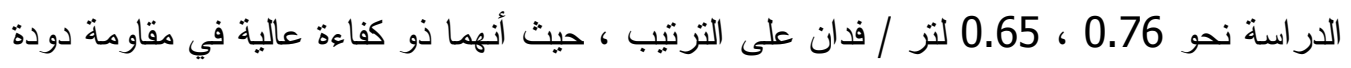
ورق القطن ، الحشائش التي تصيب محصول القطن ، وجميع هذه المبيدات غير ملوثة للبيئة ويجب

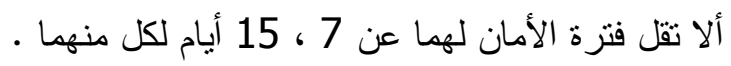

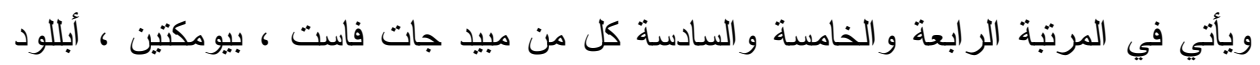

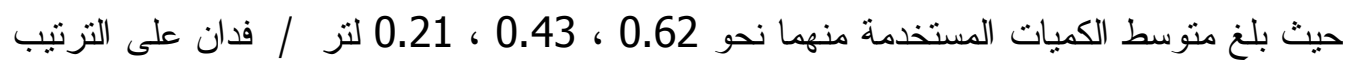
، و هذه المبيدات ذو كفاءة في مقاومة الأكاروس ، و العناكب ، و الحشرة القشرية و البق الدقيقي و هذه

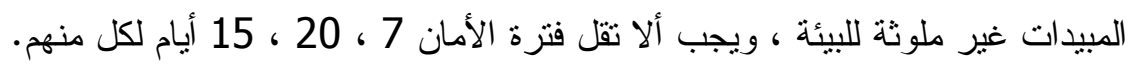


جدول رقم (15) يوضح المبيدات المستخدمة العالية الإستخدام من قبل الزراع علي محصول القطن بعينة الاراسة موسم 2016

\begin{tabular}{|c|c|c|c|c|c|c|c|c|}
\hline تلوث البيئة & تصنيف السمية طبقا & المجموعة & $\begin{array}{c}\text { فترة الأمان } \\
\text { (يوم) }\end{array}$ & الاستختيب في & متوسط الكمية & معدل الاستخدام & الأمر اض اض & المبيد \\
\hline غير ملوث & U & أخضر & 3 & 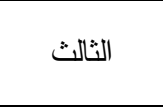 & 0.62 & 25جم/ 100لتر ماء & الحشرات الماصة ، المن & موسيبلان \\
\hline غير ملوث & $U$ & أخضر & 7 & الثناني & 0.46 & 50 جم/100لنز ماء & المن ، التربس & اوشين \\
\hline غير ملوث & $U$ & أخضر & 7 & ال الر ابع & 0.84 & 25 جم/100لتر ماء & الحشر ودة الماصة القطن ، & مارشال \\
\hline \multicolumn{4}{|c|}{ متوسط سعر الكيلو 140 جنية } & 200.4جنية & \multicolumn{4}{|c|}{ إجمالي كمية المبيدات الصلبة المستخدمة للفدان } \\
\hline غير ملوث & $U$ & أخضر & 15 & الأول ل & 0.79 & 26 سم/1003 لتر ماء & دودة اللوز ، دودة ورق & فلاكس \\
\hline غير ملوث & $\mathrm{U}$ & أخضر & 15 & الثالث & 0.65 & 40 سم3/100 لتر ماء & دودة ورق القطن & سايمكس \\
\hline غير ملوث & $\mathrm{U}$ & أخضر & 20 & الخامس & 0.43 & 20 سم/100 لتر ماء & الأكاروس و العناكب & بيومكتين \\
\hline غير ملوث & $U$ & أخضر & 7 & الثناني & 0.76 & 400 سم3/400 لتر ماء & مبيد حشائش & بريك \\
\hline غير ملوث & U & أخضر & 15 & السادس & 0.21 & 60 سم/100 لتر ماء & الحشرة القترية ، البق & 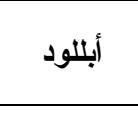 \\
\hline غير ملوث & $U$ & أخضر & 7 & 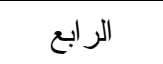 & 0.62 & 50 سم3/100 لتر ماء & الأكاروس & جات فاست \\
\hline \multicolumn{9}{|c|}{ متوسط سعر الكيلو 120 جنية } \\
\hline
\end{tabular}


ثالثاً : مقارنة بين المبيدات التقليدية والمستحدثة المستخدمة من قبل الزراع لمحصول القطن بعينة

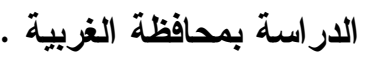
وقد تبين من جدول (16) أن متوسط كمية المبيدات المستحدثة الصلبة ( المستخدمة لمحصول القطن بعينة الدراسة أقل من منوسط المبيدات التقليدية الصلبة المستخدمة حيث تبلغ نحو 0.79 ، 0.70 1.92 كجم /فدان أي بنسبة 60 \% لكل من النمطين المستحدث و التقليدي على الترتيب ـ بينما بلغ متوسط كمية المبيدات المستحدثة السائلة المستخدمة لمحصول القطن أكبر من منوسط كمية المبيدات التقليدية السائلة المستحدثة ، حيث تبلغ نحو 3.46 ، 1.47 كجم/فدان أي بنسبة 135.4 \% لكل من من النمطين المستحدث و الثقليدي على التزتيب .

وقد تبين أن الأثز الفعال ( الكفاءة ) بالنسبة للمبيدات المستحدثة أكثر من الأثر الفعال بالنسبة للمبيدات التقليدية وذلك للمبيدات الحشرية و الحشائش ـ أما بالنسبة للتلوث البيئي للمبيدات المستحدثة و التقليدية فقد تبين من نفس الجدول أن المبيدات المستحدثة غير ملوثة ـ على عكس التقليدية فأغلبها

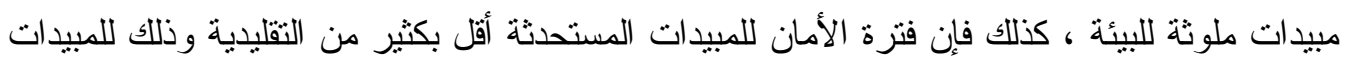

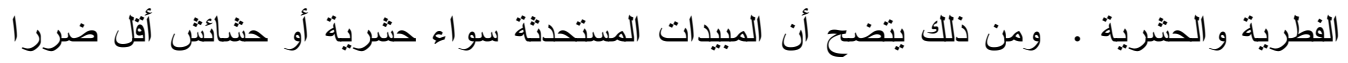
على البيئة الزر اعية سو اء بما يلوث الهو اءو والماء و التربة الزر اعية أو ما يتبقى منها على القطن من المبيدات التقليدية.

جدول رقم (16) مقارنة بين المبيدات التقليدية والمستحثثة المستخدمة من قبل الزراع علي محصول القطن بعينة الدراسة عام 2016

\begin{tabular}{|c|c|c|c|}
\hline المبيدات المستحدثة & المبيدات التقليدية & \multicolumn{2}{|c|}{ وجهة المقارنة } \\
\hline موسييلان ، اوشين ، مارشال & سبيدو ، جولدبين ، نوميلث ، كليفرون & المبيدات الصلبة & \multirow{4}{*}{ ألهم الأكواع } \\
\hline 1.92 كجم / فدان & 0.79 كجم/ فدان & المستخدمة الكمية & \\
\hline فلاكس ، سايمكس ، بيومكتين ، بريك & 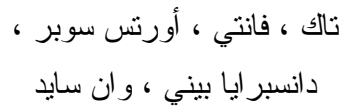 & | المبيدات السائلة & \\
\hline 3.46 لتر / فدان & 1.47 لتز / فدان & متوسط الكمية & \\
\hline أقل بشكل عام & أكثر بشكل عام & \multicolumn{2}{|c|}{ فترة الأمان } \\
\hline ذات كفاءة عالية جداً & ذات كفاءة عالية & \multicolumn{2}{|c|}{ الأثز الفعال } \\
\hline غير ملوث & ملوث & \multicolumn{2}{|c|}{ الأثر علي البيئة } \\
\hline
\end{tabular}

المصدر : جمعت وحسبت من جدولي (14 ، 15) .

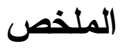

يعتبر الإنتاج الزراعى فى مصر من أهم القطاعات الإنتاجية فى مصر ، حيث أن معظم

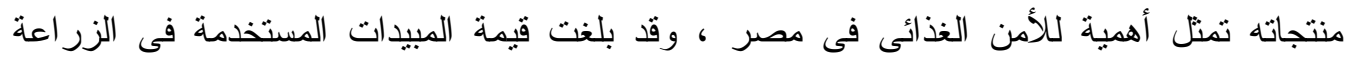

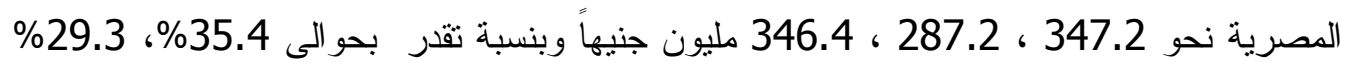


، 35.3\% لكل من المبيدات الحشرية و الفطرية و الحشائش على الترتيب من إجمالي قيمة المبيدات الزر اعية و البالغة نحو 980.8 مليون جنيها عام 2016 ـ وتركز مشكلة الدراسة علي تقييم الأثر الاقتصادي المترتب علي المكافحة المتكاملة للآفات التي تصيب محصول القطن بمحافظة الغربية . وتهدف الدراسة إلي قياس الأثر الاقتصادي لاستخدام المكافحة المتكاملة علي إنتاج محصولي القطن بمحافظة الغربية ، وتم اختيار عينة عشوائية طبقية من مزارعى محصول القطن ببعض قري محافظة الغربية بلغت نحو 120 ، 100 مشاهدة علي التزتيب . وقد أظهرت الدراسة أن أهم العوامل المؤثرة علي انتاج محصول القطن في الفئة الأولي بعينة الدراسة بمحافظة الغربية لعام 2016 هي : مقدار العمل البشري ، وكمية الثقاوي ، وقيمة المقاومة البيولوجية وبلغت المرونة الإنتاجية الإجمالية نحو 0.867 مما يعني سيادة العلاقة الإنتاجية المتتاقصة ، كما بلغت قيمة الناتج الحدي لتلك العناصر نحو 87.0 ، 249.3 ، 873.5 جنيه / قنطار علي الترنيب ، بينما بلغ سعر الوحدة من العنصر نحو 42.19، 5.39 ، 50.0 جنيه / وحدة علي التزتيب ـ أما في الفئة الثانية فتنين أن أهم العو امل المؤثزة علي إنتاج القطن هي : مقدار العمل الآلي (رى) ، وكمية التقاوي ، وقيمة المقاومة الكيماوية وبلغت المرونة الإنتاجية الإجمالية

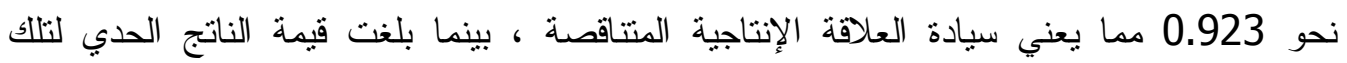

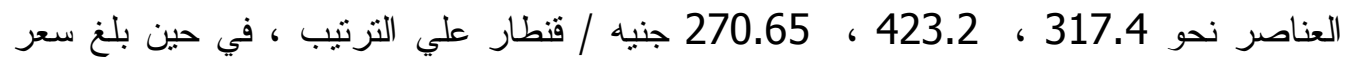

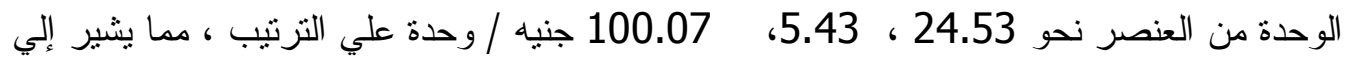
كفاءة تلك العناصر بالدالة في إنتاج القطن في فئتي الدراسة ، ولكن ماز ال بالإمكان زيادة كفاءة الداء

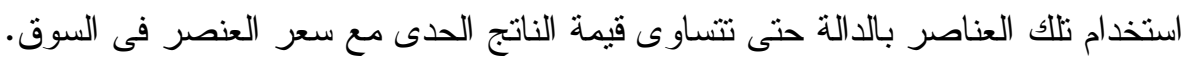

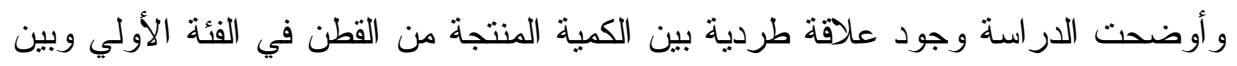
كل من المقاومة الكيماوية ، وقيمة المقاومة البيولوجية المستخدمة ـ وبلغت المرونة الإنتاجية الإجمالية نحو 0.635 ، كما بلغت قيمة الناتج الحدي لهذه العناصر نحو 167.5 ، 52.5 جنيه 52.5 /وحدة، أما متوسط سعر الوحدة فبلغ نحو 112.24 ، 18.97 جنيه / وحدة علي الترتيب ـ أما في الفئة الثانية فقد بلغت المرونة الإنتاجية لهذه العناصر نحو 0.128 ، 0.384 علي الترتيب ، بينما بلغت قيمة الناتج الحدي نحو 510 ، 142.5 جنيه /وحدة ، كما بلغ متوسط سعر الوحدة نحو 100.1 ، 58.95 جنيه / وحدة علي الترتيب ، مما يشير إلي كفاءة عنصري المكافحة المتكاملة

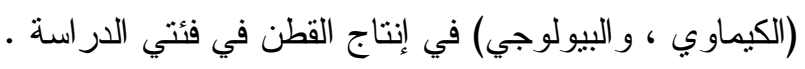
كما أوضحت الدراسة وجود علاقة طردية بين قيمة الناتج الرئيسي من القطن في الفئة الأولي وبين كل من المقاومة الكيماوية وقيمة المقاومة البيولوجية المستخدمة وبلغت المرونة الإجمالية

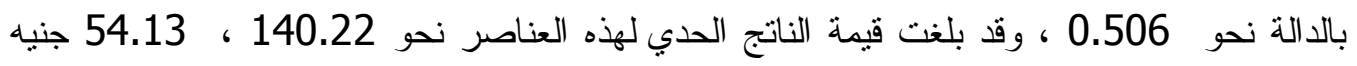
/وحدة ، كما بلغ منوسط سعر الوحدة نحو 112.24 ، 18.97 جنيه / وحدة علي التزتيب ـ أما في 38.

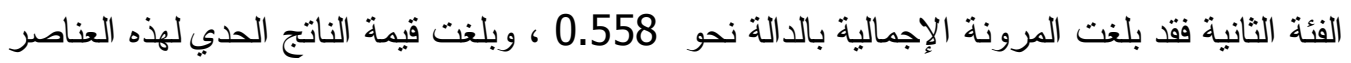
نحو 120 ، 151.3 جنيه /وحدة ، كما بلغ منوسط سعر الوحدة نحو 100.1 ، 158.95 جنيه / 5 |

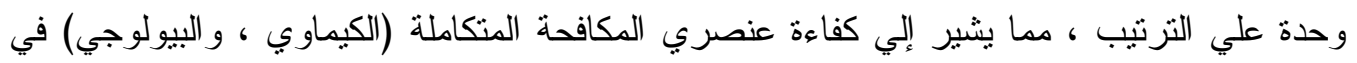


إنتاج القطن في فئتي الدراسة ، ولكن لاز ال بالإككان زيادة تلك الكفاءة حتي يتساوي قيمة الناتج الحدي للعنصر مع سعره السائد في السوق •

كما تم در اسة بعض المقاييس الإقتصادية لفدان محصول القطن بفئتي عينة الدر اسة بمحافظة الغربية وتبين أن إجمالي تكاليف المكافحة المتكاملة للفدان في الفئتين الأولي والثانية بلغ نحو 1403.8 ، 1360.2 جنيه بنسبة تغير بلغت نحو(- 3\%) ، وبلغ عائد الجنيه المستثمر نحو 0.978 ، 1.049 جنيه في الفئتين الأولي والثانية علي التزتيب، وبلغ معدل الكفاءة الإقتصادية في انتاج فدان القطن في فئتي الدراسة نحو 197.8\% ، 204.9\% علي الترتيب، و هذا يعكس وفور ات السعة في الفئة الثانية (فدان فأكثر) عن الفئة الأولي (الأفل من فدان) .

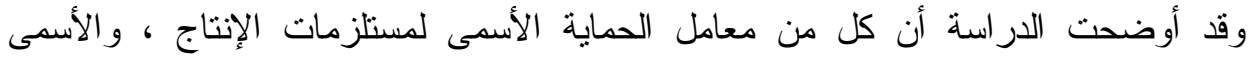
للمنتجات ، والأسمى للمقاومة البيولوجية ، ومعامل الحماية الفعال لمحصول القطن بصفة الدراسة

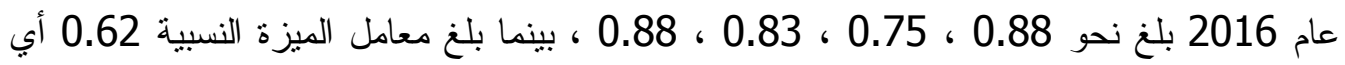
أنه يوجد ميزة نسبية لمصر في إنتاج القطن، وتنشير نتائج تحليل مصفوفة السياسات الإنتاجية لمحصولي القطن موسم 2016 وجود آثار سلبية على إجمالي العائد الفدانى و القيمة المضافة ، و وقد

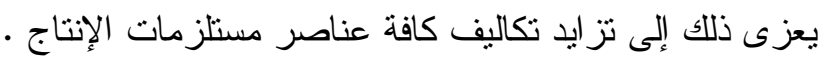
كما بينت الدراسة أن أهم المبيدات المستخدمة من قبل الزراع لمحصول لمبل القطن بعينة الدراسة للمبيدات التقليدية بمحافظة الغربية فقد جاء فى المرتبة الأولى مبيد سبيدو بكمية 0,29 كجم/فدان بفترة أمان 20 أيام، يليه فى المرنبة الثانية كوبر كليفرون بكمية 0,22 كجم /فدان بفترة أمان 10 ايام، وهما مبيدان ملوثان للبيئة ، أما المبيدات المستحدثة فيأتي فى المرتبة الأولى مارشال بكمية 0,84كجم/ فدان بفترة أمان 7 أيام، يليه فى المرتبة الثانية مبيد موسيبلان بكمية 0,62 كجم فئن /فدان بفترة أمان 10 أيام، وهما مبيدان غير ملوثان للبيئة، ونخلص من ذلك أن المبيدات المستحدثة أقل ضرراً للبيئة من المبيدات التقليدية.

\section{التوصيات}

1- ضرورة نو عية الزر اع بأضر ار المبيدات على صحة الإنسان و الحيوان و النبات و البيئة0 2- التوسع فى استخدام أسلوب المقاومة البيولوجية بهدف زيادة جودة البرة القطن من ناحية، وخفض تكلفة المقاومة الكيماوية من ناحية اخرى للحفاظ علي الصحة العامة . 3- يجب وضع برنامج لنتريب مزارعي القطن علي الإنتخدام الأمثل للمبيدات فى الحدود المسموح بها لعامها عالمياً للحفاظ علي صحة الإنسان و الحيو ان و البيئة . 4- فرض ضريبة على مستخدمى المبيدات عالية السمية، مما يساهم فى تحول الزر اع إلى استخدام الزراعة النظيفة أو وضع قانون يجرم إستخدام المبيدات الغير صالحة لتأثير ها علي الصحة العامة .

5- تحفيز زراع القطن الأقل استخداماً للمبيدات التقليدية و المتبعين لأسلوب المكافحة المتكاملة

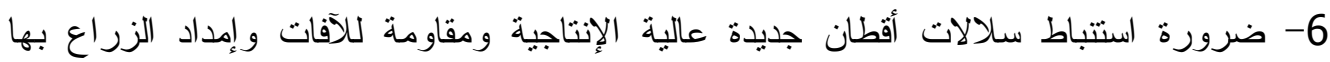
وتوفير ها للمز ارع كحافز لزيادة مساحة القطن المزروعة في مصر . 


\section{الملاحق}

جدول ملحق رقم (1 ) : بنود التكاليف الإنتاجية الفدانية وصافي العائد من محصول القطن بعينة الدر اسة عام 2016 في ظل استخدام المقاومة البيولوجية مقارناً بعام 1990 ( قبل التطبيق )

\begin{tabular}{|c|c|c|c|c|}
\hline \multicolumn{2}{|c|}{ 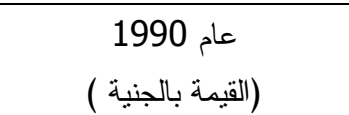 } & \multicolumn{2}{|c|}{ 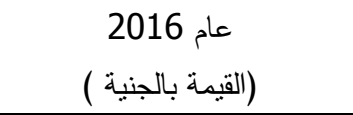 } & \multirow[t]{2}{*}{ 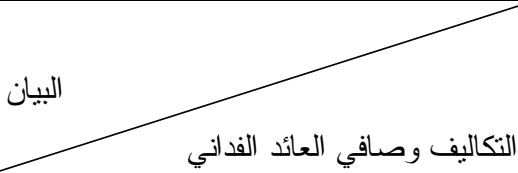 } \\
\hline بسعر الظل * & بسعر السوق & بسعر الظل * & بسعر السوق & \\
\hline & & & & (أ) مستلزمات إنتاج لها تجارة خارجية \\
\hline 6.89 & 6.0 & 175.53 & 167.17 & - تكلفة تقاوي \\
\hline 99.78 & 60.0 & 692.14 & 629.22 & - تكلفة أسمدة كيماوية \\
\hline 25.69 & 13.0 & 565.52 & 471.27 & - تكلفة مبيدات \\
\hline- & - & 75.20 & 62.67 & 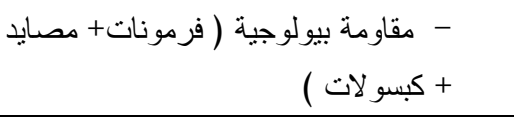 \\
\hline 132.36 & 79.0 & 1508.39 & 1330.33 & 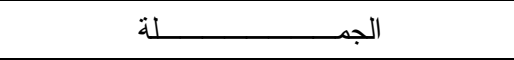 \\
\hline & & & & (ب) مستلزمات إنتاج ليس لها تجارة خارجية \\
\hline 85.0 & 85.0 & 51.69 & 51.69 & - تكلفة سماد بلدي \\
\hline 85.0 & 85.0 & -- & -- & - مصاريف نثرية \\
\hline 170.0 & 170.0 & 51.69 & 51.69 & 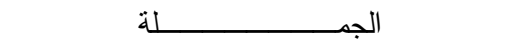 \\
\hline & & & & (ج) عناصر إنتاج محلية \\
\hline 209.0 & 418.0 & 1832.89 & 2735.65 & - أجور عمل بشري ( تشمل تكلفة المقاومة \\
\hline- & - & 12.24 & 12.24 & - أجور عمل حيو اني \\
\hline 114.7 & 99.0 & 904.12 & 821.93 & - أجور عمل آلي \\
\hline$\left({ }^{(* *)} 1901.0\right.$ & 129.0 & (**) 10150 & 4423.15 & - إيجار فدان القطن \\
\hline 2224.7 & 646.0 & 12899.25 & 7992.97 & الجــــــا \\
\hline 2527.06 & 895.0 & 14459.3 & 9374.85 & - إجمالي التكاليف الإنتاجية الفدانية \\
\hline- & 5.22 & - & 7.47 & - الإنتاجية الفدانية (قنطار متري ) \\
\hline- & 250.0 & - & 2527.84 & - السعر المزرعى ( جنية / قنطار) \\
\hline 3007.16 & 1305.0 & 25303.22 & 18883.00 & - إجمالي العائد \\
\hline 480.1 & 410.0 & 10843.89 & 9508.15 & - صافي العائد الفذانى \\
\hline
\end{tabular}

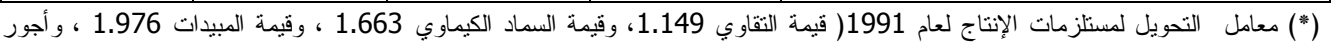

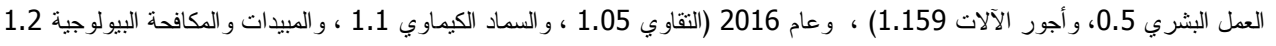

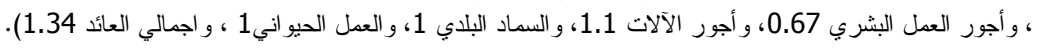

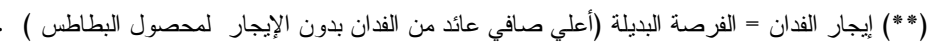

1- - وزارة الزر اعة واستصلاح الأراضي ، قطاع الثئون الإقتصادية ، نشيرة الإحصاءات الزراعية.

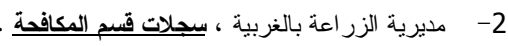

World Bank, The Economics of Project Analysis Washington D-C1991. Page 220. 


\section{المراجع}

1- أثرف شبل محمد يونس ، تقييم إقتصادى للآثار البيئية لبعض مشروعات التتمية الزر اعية

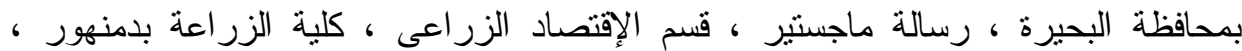

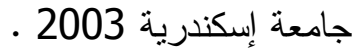

2- البرنامج المصرى الألمانى لتطوير قطاع القطن ، تحليل أنظمة المكافحة المتكاملة للأفات فى

إنتاج القطن 1998

3- الجهاز المركزى للتعبئة العامة و الإحصاء ، المركز القومى للفئة المعلومات ، أعداد مختلفة.

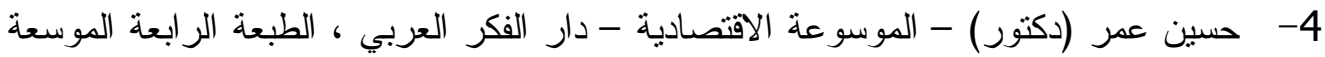

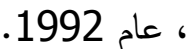

5- حنان عبد المنعم محمد زهر ان ، إقتصاديات إستخدام المبيدات وأثز ها على البيئة فى محافظة

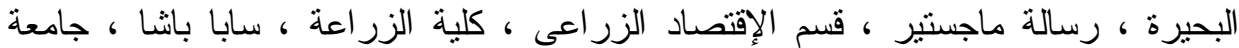

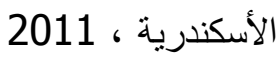

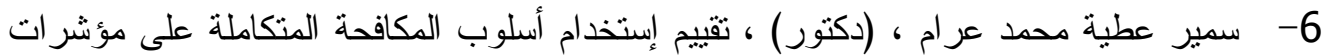

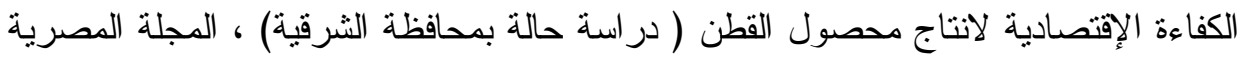

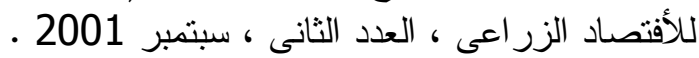

7- عر أحمد بدر ( دكتور ) ، تقييم الآثار الإقتصادية للمكافحة المتكاملة على إنتاج القطن فى القيل

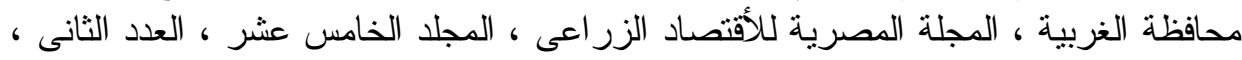

يونيو 2005 .

8- على رزف مصطفى ( دكتور) ، دراسة إقتصادية لتقييم أثنار المكافحة البيولوجية لآفات القطن

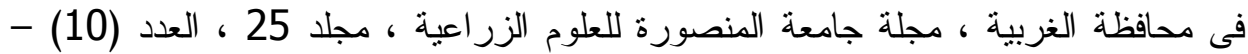

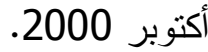

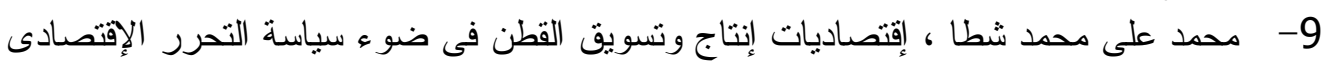

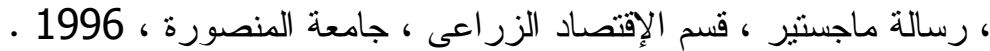

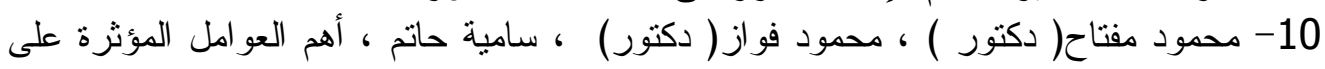

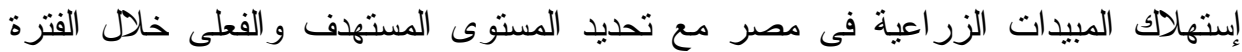

(1990- 2011) ، المجلة المصرية للأقتصاد الزر اعى ، المجلة (22) ، العدد (3) سبتمبر الفير

11- مديرية الزر اعة بالغربية ، إدارة مكافحة الآفات ، سجلات الادارة ، بيانات غير منشورة ،

سنو ات مختلفة

12- مصطفى عبد اللطيف العباس ، التأثير ات الضارة للمبيدات على الإنسان و البيئة وكيفية الحد

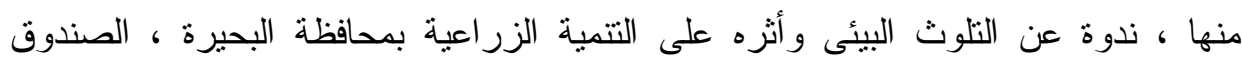

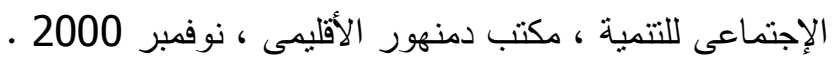

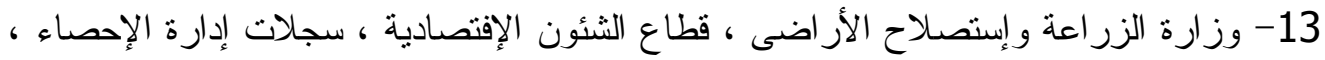

بيانات غير منشورة .

14- Cotton world statistics, Bullation of international cotton advisory committee , may, 1997

15- Frank ellis, Agricultural policies in developing countries, 1992.

16- World Bank, The Economics of Project Analysis Washington , D-C1991. Page 220. 